\title{
A Dynamic Optimization Tool to Size and Operate Solar Thermal District Heating Networks Production Plants
}

\author{
Régis Delubac*, Sylvain Serra (D), Sabine Sochard and Jean-Michel Reneaume \\ LaTEP (Laboratory of Thermics, Energetics and Processes), E2S UPPA, Universite de Pau et des Pays de l'Adour, \\ 64000 Pau, France; sylvain.serra@univ-pau.fr (S.S.); sabine.sochard@univ-pau.fr (S.S.); \\ jean-michel.reneaume@univ-pau.fr (J.-M.R.) \\ * Correspondence: regis.delubac@univ-pau.fr
}

Citation: Delubac, R.; Serra, S.;

Sochard, S.; Reneaume, J.-M. A

Dynamic Optimization Tool to Size and Operate Solar Thermal District Heating Networks Production Plants. Energies 2021, 14, 8003. https:// doi.org/10.3390/en14238003

Academic Editor: Azharul Karim

Received: 25 October 2021

Accepted: 23 November 2021

Published: 30 November 2021

Publisher's Note: MDPI stays neutral with regard to jurisdictional claims in published maps and institutional affiliations.

Copyright: (c) 2021 by the authors. Licensee MDPI, Basel, Switzerland. This article is an open access article distributed under the terms and conditions of the Creative Commons Attribution (CC BY) license (https:// creativecommons.org/licenses/by/ $4.0 /)$.
Abstract: The aim of the ISORC/OPTIMISER project is to increase and improve the use of solar thermal energy in district heating networks. One of the main tasks of the project is to develop an optimization tool for the sizing and operation of a solar district heating network. This is the first optimization tool using an open-source interface (Julia, JuMP) and solver (Ipopt) to solve nonlinear problems. This paper presents the multi-period optimization problem which is implemented to consider the dynamic variations in a year, represented by four typical days, with an hourly resolution. The optimum is calculated for a total duration of 20 years. First, this paper presents the modeling of the different components of a solar district heating network production plant: district network demand, storage and three sources, i.e., a fossil (gas) and two renewable (solar and biomass) sources. In order to avoid prohibitive computational time, the modeling of sources and storage has to be fairly simple. The multi-period optimization problem was formulated. The chosen objective function is economic: The provided economic model is accurate and use nonlinear equations. Finally the formulated problem is a nonlinear Programming problem. Optimization of the studied case exhibits consistent operating profiles and design. A comparison is made of different types of storage connection at the production site, highlighting the relevance of placing the storage at the solar field outlet. The optimum configuration supplies $49 \%$ of demand using solar energy, achieving a renewable rate of $69 \%$ in combination with the biomass boiler.

Keywords: solar thermal energy; district heating networks; multi-sources; economic nonlinear optimization; Julia (JuMP)

\section{Introduction}

\subsection{Context}

Reducing $\mathrm{CO}_{2}$ emissions is one of the major challenges of the 21st century. In France, the tertiary/residential sector represents almost $45 \%$ of national energy consumption [1] (66 tonnes of oil equivalent) and $27 \%$ of greenhouse gas emissions. In this sector, $11 \%$ of consumption still comes from petroleum products, 30\% from natural gas and $45 \%$ from mainly nuclear-based electricity. Heating represents $66 \%$ of a household's energy consumption and the production of domestic hot water $11 \%$ [2]. It is in this context that the development of urban heating networks makes sense and especially fourth generation networks, which, among other things, are reducing network temperatures. This reduction facilitates the use of renewable energies across wider geographical areas [3-6].

Notably, solar district heating networks (SDHNs) are an interesting solution for heating buildings for many reasons $[7,8]$ :

- Reduction in $\mathrm{CO}_{2}$ emissions;

- Centralization of heat production, which introduces a scale effect, reducing costs;

- Delivery of heat to different kinds of buildings with different heating loads that can be pooled. 
Improving the integration of solar heating into DHNs is a subject that started to be studied in the 1980s [9] with the aim of improving its interaction with other sources and seasonal storage. The IEA proposes a review of the 40 years of existence of SDHNs [10]. It highlights that the use of solar energy in DHNs is very relevant, although regional energy policy and regulatory frameworks, in combination with a general lack of awareness about solar heating among stakeholders, are the main obstacles to developing SDHNs. Numerical tools could be an efficient way to overcome this lack of awareness. Some are already commonly used (such as TRNSYS), but they hardly use real mathematical optimization. In addition, most of the applications described in the IEA review were not suitably optimized, mainly because computer power did not allow for real digital optimization 40 years ago and also because mathematical optimization makes the use of numerical tools trickier. However, optimizing SDHNs can be very relevant since the suitability of using solar energy in DHNs has already been proven: Numerical optimization tools could help to make the use of solar energy more efficient.

In this context, the ISORC project (a consortium including design offices-Tecsol, NewHEAT and Sermet_-and a research laboratory_LaTEP_-supported by ADEME) aims to increase and develop solar thermal energy in existing and new district heating networks (DHNs). Among the different tasks of the project, the one led by the LaTEP is to develop a numerical optimization tool devoted to the use of solar energy in the mix energy dedicated to supply DHNs.

\subsection{Optimization Issues of State-Of-The-Art District Heating Networks and Tools Used to Address the Problem}

The optimization of heating and cooling networks is a subject that has been covered in numerous articles, which in turn have been summarized in various reviews. Figure 1 shows the strong tendency to use mathematical optimization in heat networks over the past decade. Sameti and Haghighat [6] carried out a review of DHN optimization studies divided into four topics: connection of sources to the network, network configuration (size and number of each component), operation and scheduling and subsystem building blocks (focused on specific technical aspects). Whatever the topic, in most of the studies, the formulation of the optimization problem led to a mixed integer linear programming (MILP) formulation, which was then solved with commercial solvers. The authors concluded that considerable computational times were required for large networks. Gao et al. [11] carried out a review of state-of-the-art optimization methods used for energy cogeneration systems, which therefore included DHNs. They noted in particular a growing tendency to use solar heat in new DHNs. Gao et al. [11] noted that there was a need for more in-depth research on small-scale networks and on the economic models used to optimize DHNs, in order to facilitate their development. Finally, Wang et al. [12] recently assessed the performances of the optimization methods used in DHNs. They outlined the methods along with their purpose and environment, concluding, like Sameti and Haghighat [8], that the MILP approach is most often used in the MATLAB/Simulink environment in order to minimize total costs. The authors highlight the need to be aware of data such as flow rates, temperatures and energy levels in order to better assess network performance and better identify possibilities for optimization.

Here we present the most relevant optimization studies, starting with steady-state optimization followed by different dynamic modeling approaches, and finally we explain the multi-period approach.

Considering steady-state optimization in more detail, Mertz et al. [13] developed a mixed integer nonlinear programming (MINLP) optimization methodology for the topology and design of fourth generation DHNs, including the choice of technologies and of the consumers to be supplied. Again in MINLP optimization, Marty et al. modeled a cogeneration system including an ORC and a heating network. They studied different objective functions (economic [14] and exergetic [15]) and finally demonstrated the advantage of carrying out a multi-objective optimization taking both these aspects into consideration [16]. Using these steady-state approaches, it is possible to optimize sizing, but as they are based 
on constant operation, they are not able to optimize the dynamic operation of a network. This is essential, however, when considering intermittent renewable energy sources and thermal storage.

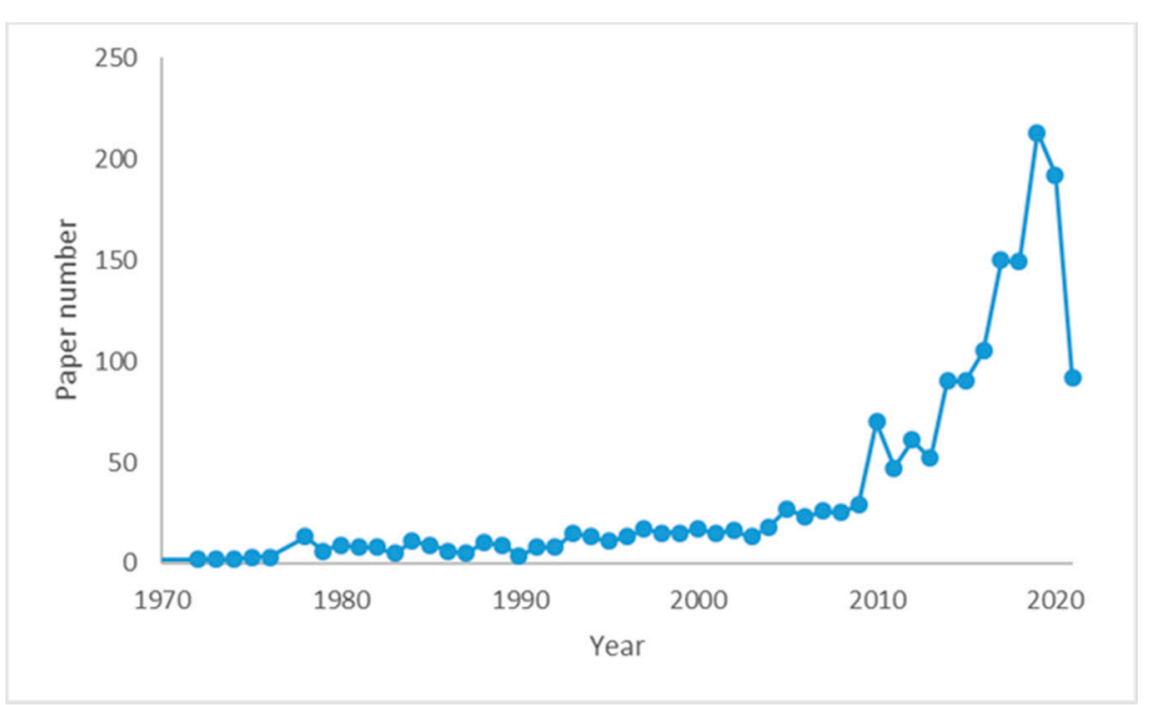

Figure 1. Yearly paper distribution mentioning district heating optimization (Scopus, May 2021).

With the dynamic approach it is also possible to optimize operation by taking the temporal variability of certain variables into account. Powell et al. [17-19] modeled and optimized a mid-season thermal plant with an orthogonal collocation method. As they introduced a model for a solar thermal parabolic mirror, a model for thermal energy storage (TES) was also implemented with hot and cold volumes. The dynamic model was then transformed in an algebraic system using orthogonal collocations and solved as a nonlinear programming (NLP) optimization. The same methodology was also applied to dynamically optimize a hybrid solar thermal and fossil fuel system. The authors showed that coupling solar with fossil fuels could increase the share of solar thermal energy in the global energy mix. Again with an NLP-type problem, Scolan et al. [20] optimized the operation of a low-temperature solar plant by minimizing operating costs over a 5-day time period. The dynamic model is discretized into an algebraic system using the orthogonal collocations on finite elements method. The studies mentioned above present optimized heat production, while others study the network in more detail by considering production in a simplified way [13,21-23]. Nova-Rincon et al. [21] used 2D orthogonal collocation to dynamically optimize the operation of a cooling network to obtain flow rate and temperature profiles to meet consumer demands.

One way to discretize time differential equations can lead to a multi-period formulation. In multi-period approaches, some equations are considered as steady state, while others can be discretized on the selected time step. In literature, many studies on energy management have used the multi-period approach to take into account the variability of energy prices and the availability of sources to ensure the operability performance of the system at the early design stage [24,25]. For example, Morvaj et al. [26] optimized a DHN layout and its sizing and functioning with an hourly time step on typical days to optimize both cost and $\mathrm{CO}_{2}$ emissions using a MILP-type formulation. Carpaneto et al. [27] used a MILP formulation to optimize solar thermal field size by considering an economical objective function. They concluded that solar inputs reduce management costs during mid-season periods and summer when solar thermal energy can replace the use of boilers. The case they studied in Northern Italy demonstrated how the storage operation could allow solar energy to cover total demand. Solar thermal energy integration has also been studied in an industrial sector [28,29] using MILP approaches. This showed that, in a combined heat and power (CHP) system, the optimized solar field produced around 55\% of user annual demand. All these problems were formulated as MILP since convergence 
is easier than for MINLP formulations. However, this suggests that all models had to be linearized, which sometimes leads to strong assumptions. In particular, for equations representing economic models it is difficult to take account of the effects of scale, which can lead to a strongly nonlinear reduction in costs, depending on the size of the systems. Calculating temperatures with a linear formulation using Grossmann's "transhipment" method $[30,31]$ increases the number of variables considerably.

Another limitation on the use of these tools in the industrial field is the complexity of handling this analysis, which is usually carried out in an academic context. Despite the high number of solar DH systems in countries as Denmark, the development of those technologies is still limited across the world. When considering the commercial tools used to study the integration of renewable energies in DHNs, it soon becomes clear that there is a real need for a quick and simple tool which is nevertheless still precise. This is also the conclusion reached by Connolly et al. [32] or more recently by Limpens et al. [33,34]. Connolly et al. [32] carried out a study of 37 tools. Most focus on electricity planning and perform simulations rather than mathematical optimization. There are some accurate commercial tools, such as EnergyPLAN or TRNSYS, which are mainly used for simulation even though they propose optimization solvers $[35,36]$. Relevant open-source tools such as Balmorel can be found in the Open Energy Modelling Initiative (Openmod) community [37]. Finally, A. Le Denn (Tecsol), carried out a study of calculation tools and methods used for solar district heating. None of them use mathematical optimization as most cannot be used by a non-expert.

The same conclusions were also reached by Limpens et al. [33], who created a crosssectoral (electricity, heat and transport) open-source optimization tool, EnergyScope TD. It uses different objective functions (economic, $\mathrm{CO}_{2}$ emissions, renewable percentage) with a MILP formulation, to optimize the design and operation of energy systems taking all energy carriers into account, with an hourly resolution and for an urban to regional scale. The open-source GLPSOL solver can be used, but performances (speed) are improved by the use of a commercial MILP solver such as CPLEX.

\subsection{Objectives of the Present Work}

The tool presented here is written in an open-source language (Julia [38] and its optimization package JuMP [39]) and uses open-source solvers but with the possibility of using commercial ones. The creation of this tool responds to an industrial demand in order to respond to projects in a more competitive way, i.e., more precisely. It studies solar district heating networks (SDHNs) with an NLP formulation to model all components more accurately than in MILP approaches. It needs to be fast, open-access and easy to use by different kinds of users (expert or not), such as communities, engineering consultants and companies.

This paper presents a nonlinear formulation to model a multisource DHN, including solar thermal energy. Certain production elements can be modeled in more detail due to the NLP approach (storage volume, solar field area, etc.) as with the flow rate and the network and storage temperatures that can be calculated and settled at different levels. The decision to use the NLP approach allows for better precision in the physical models and highly nonlinear tendency of the cost functions due, among other things, to a scale effect. The larger the system, the lower the unit cost. On the other hand, the resolution is more difficult, requiring the development of a more elaborate resolution strategy. To our knowledge, an optimization tool for the sizing and operation of such multisource DHNs with an NLP approach has not been studied yet. The novelty lies in three interrelated issues: a multisource approach, including solar thermal and NLP solving, with an open-source interface and solver.

In the following, we first present the models used to represent the SDHN and in particular the heat production site. This consists of inter-seasonal storage and three production sources, a gas boiler, a biomass boiler and a solar field. Next, the resolution methodology is 
presented and applied to a DHN with inter-seasonal storage to study the different possible storage connections.

\section{Methodology}

The tool presented here solves a multi-period NLP optimization problem. The dynamic DHN model results in a set of differential equations (objective function and constraints) which are discretized. At each time step (period) the system is assumed to be in a steady state. As shown in Figure 2, the system includes three heat sources (biomass boiler, gas boiler and solar thermal plant) connected in series as in some existing SDHNs and a thermal storage unit connected in parallel. For each period (denoted " $i$ "), parameters such as DHN demand, solar energy availability and ambient temperature are known. Next, the optimization tool calculates the optimal size for each source (over the whole integration period) and operation variables (temperatures, mass flow rates, etc.) for each period. The objective function, which aims to minimize the total cost, is resolved for a total duration of 20 years. Since this study focuses on multi-source optimization, all of the DHN consumers are modeled in this study by a single substation, which represents total heating demand, as in $[40,41]$.

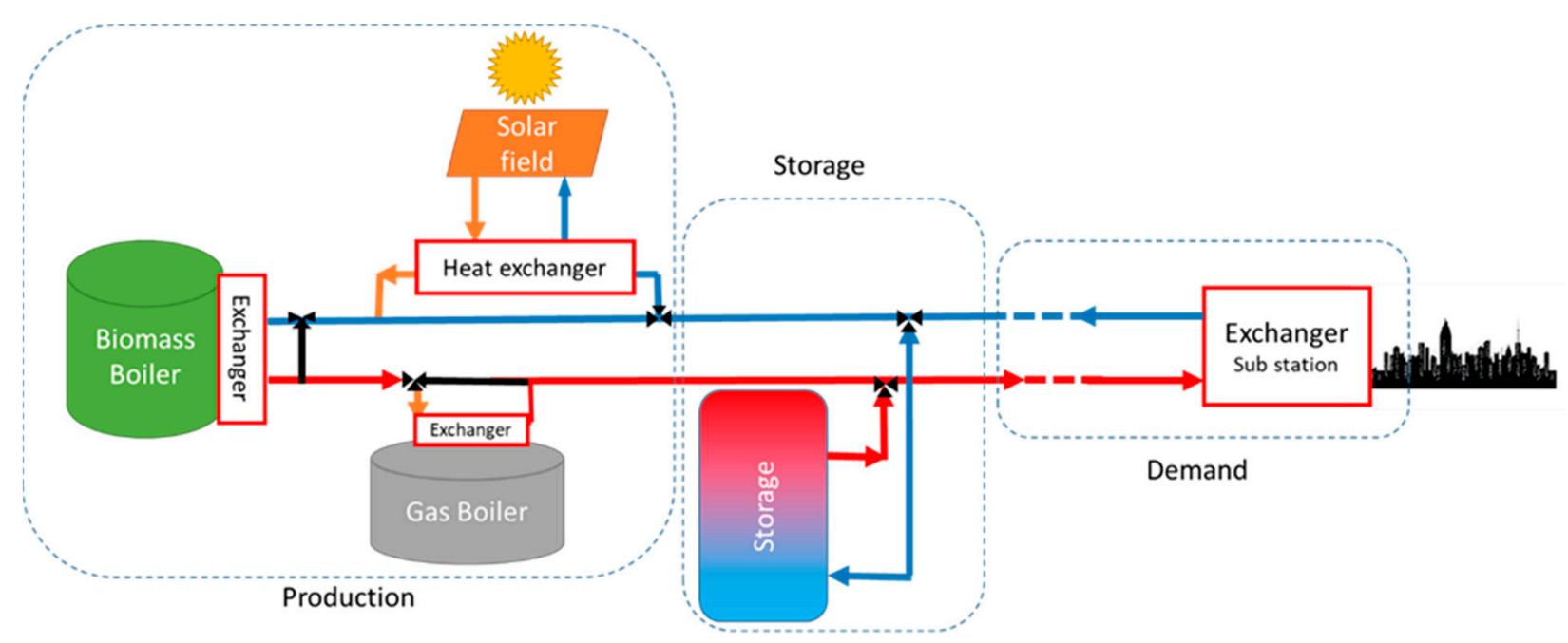

Figure 2. Diagram of the modeled system.

\subsection{Creation of Typical Days}

Due to the large number of variables and constraints necessary for the correct representation of the system over a period, optimizing every day in the year is difficult to achieve, especially if the aim is to have short calculation times. Hence, it is necessary to simplify the problem by trying to find a compromise between precision of results and calculation time. There are various methods in the literature for defining typical days. They have been summarized by different authors [33,42,43]. The method used by DominguezMunoz et al. [44] was adapted with the aim of representing a year as typical days with an hourly time step: one day in winter, one day in summer and one day representing mid-season, i.e., spring and autumn, which is therefore be used twice. This is a method for creating typical days using mathematical optimization. The optimized variables are network demand $P_{\text {demand,car }}$, amount of sunshine $G_{c a r}$ and outside temperature $T_{\text {ext,car }}$. The purpose of the optimization is therefore to create typical days that minimize the objective function (Equation (1)) written as the sum of the squared deviations between the day that has been created and all the other days in the season provided by a database (network demand, amount of sunshine and outside temperature being furnished in this database for one year with an hourly time step). The letter " $l$ " represents the index for the period that 
here represents one hour of a $24 \mathrm{~h}$ day, " $k$ " is the season index denoted by 1 to 3 and " $j$ " represents the index for the day of the season considered Seas.

$$
\begin{aligned}
& \text { obj } \mathrm{P}_{\text {car }, k}=\min _{P} \sum_{j}^{\text {Seas }, k} \sum_{l}^{24}\left(P_{\text {demand }, c a r, k, l}-P_{\text {demand }, j, k, l}\right)^{2}, \forall k \in[1,3] \\
& \operatorname{obj} G_{c a r, k}=\min _{G} \sum_{j}^{\text {Seas }, k} \sum_{l}^{24}\left(G_{c a r, k, l}-G_{j, k, l}\right)^{2}, \forall k \in[1,3] \\
& \operatorname{obj} \mathrm{T}_{\text {car }, k}=\min _{T} \sum_{j}^{\text {Seas }, k} \sum_{l}^{24}\left(T_{\text {ext,car }, k, l}-T_{\text {ext } j, k, l}\right)^{2}, \forall k \in[1,3]
\end{aligned}
$$

This minimization is therefore carried out 3 times in order to create a typical profile for winter $(k=1$, Seas $=90)$, summer $(k=2$, Seas $=92)$ and mid-season $(k=3$, Seas $=183)$.

To simplify the writing of the equations, the season index " $k$ " is not written in the following equations. The index " $i$ " indicates the time index for each typical day in all seasons by taking values from 1 to 96 (1-24: winter, 25-48: mid-season, 49-72: summer and 73-96: mid-season).

\subsection{Model of the DHN}

In this study, the heating network is very much simplified. It is represented by an equivalent substation which replaces the whole network. For each period, demand $P_{\text {demand, } i}$ must be satisfied (Equation (4))

$$
P_{\text {demand }, i}=\dot{m}_{\text {district }, i} C_{p} \eta_{\text {network }}\left(T_{\text {outward }, i}-T_{\text {return }, i}\right)
$$

with $\eta_{\text {network }}=0.9$ the average annual efficiency of a heating network taking into account in particular heat losses. $\eta_{\text {network }}$ is a value supplied by the various partners of the ISORC project based on their expertise and knowledge. $T_{\text {outward }, i}$ and $T_{\text {return }, i}$, are the outward and return temperatures of consumers.

\subsection{Model of the Heat Production Systems}

For each period, the sizing of heat production sources and storage must respect Equation (5) $\left(P_{\text {stor }, i}\right.$ is negative in the case of storage and positive in the case of discharge of storage):

$$
\left(P_{\text {sol }, i}+P_{\text {biom }, i}+P_{\text {gas }, i}+P_{\text {stor }, i}\right) \eta_{\text {network }}=P_{\text {demand }, i}
$$

Details of power by type of production unit are given in the following subsections.

\subsubsection{Solar Field}

The solar field (shown in Figure 3) is modeled by a single equivalent solar panel [45]. The norm EN12975 equation is used to calculate the outlet temperature $T_{\text {out }, \text { pan }, i}$ from the inlet temperature $T_{i n, p a n, i}$ using Equations (6) and (7):

$$
\begin{gathered}
\dot{m}_{\text {sol }, i} C_{p}\left(T_{\text {out }, p a n, i}-T_{i n, p a n, i}\right)=A_{p a n}\left[\eta_{0} G_{i}-\alpha_{1}\left(T_{a v, i}-T_{e x t, i}\right)-\alpha_{2}\left(T_{a v, i}-T_{e x t, i}\right)^{2}\right] \\
T_{a v, i}=\frac{T_{i n, p a n, i}+T_{o u t, p a n, i}}{2}
\end{gathered}
$$

$A_{\text {pan }}$ represents the total surface area of the panel, $\dot{m}_{s o l, i}$ the flow rate for solar irradiance $G_{i}$ and coefficients $\eta_{0}, \alpha_{1}$ and $\alpha_{2}$ are dependent on the characteristics of the panel $\left(\eta_{0}=0.906, \alpha_{1}=3.36 \mathrm{~W} / \mathrm{m}^{2} \mathrm{~K}\right.$ and $\alpha_{2}=0.0109 \mathrm{~W} / \mathrm{m}^{2} \mathrm{~K}^{2}$, issued from the website "the solar kermark"). 


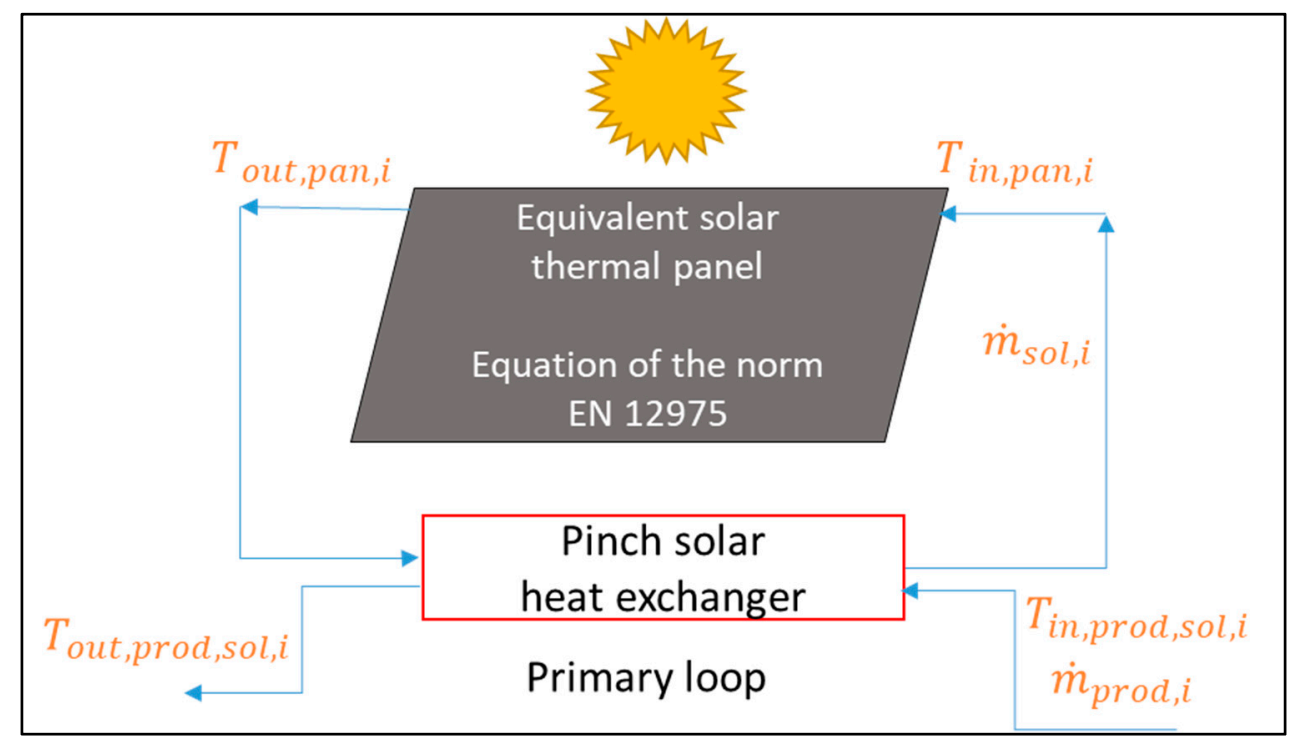

Figure 3. Schematic diagram of the solar thermal model.

The exchanger between the solar field and the primary loop is modeled to respect a given pinch (Equations (8) and (9)):

$$
\begin{aligned}
& \dot{m}_{\text {sol }, i}\left(\left(T_{\text {out }, \text { pan }, i}-T_{\text {out }, \text { prod }, \text { sol }, i}\right)-\text { pinch }\right) \geq 0 \\
& \dot{m}_{\text {sol, }, i}\left(\left(T_{\text {in }, p a n, i}-T_{i n, p r o d, s o l, i}\right)-\text { pinch }\right) \geq 0
\end{aligned}
$$

The flow rate $\dot{m}_{s o l, i}$ appears in Equations (8) and (9) to allow for two operating states:

1. If the output temperature of the solar field is too low to be able to exchange with the network while respecting the pinch, $\dot{m}_{\text {sol, } i}$ becomes zero so that Equations (8) and (9) remain verified. In reality, during these periods the output temperature of the solar field can gradually increase. Our model is quasistatic; thus, our modeling leads to $T_{i n, p a n, i}=T_{\text {out }, \text { pan }, i}$, and the solution of Equation (6) leads to an average equilibrium temperature of the field for the considered period.

2. If the temperature is high enough, $T_{o u t, p a n, i}, T_{i n, p a n, i}$ and $T_{a v, i}$ are calculated using Equations (6) and (7) and are able to deliver heat to the network provided that the fixed pinch is respected. In this study, the pinch value is set at pinch $=2 \mathrm{~K}$.

\subsubsection{Boilers}

3 Two kinds of boiler are modeled: a wood-fueled boiler (called biomass boiler) and a gas boiler. They are modeled by Equations (10)-(12).

$$
P_{\text {boil, } p r o d, i}=\dot{m}_{\text {prod,boil }, i} C_{p}\left(T_{\text {out }, \text { boil }, i}-T_{\text {in }, \text { boil }, i}\right)
$$

$P_{b o i l, p r o d, i}$ is the boiler power actually supplied to the network. This power corresponds to the power of the boiler $P_{b o i l, i}$ multiplied by efficiency $\eta_{b o i l}$ (Equation (11)) which depends on the boiler type (boil = biom or gas).

$$
P_{b o i l, p r o d, i}=P_{b o i l, i} \eta_{b o i l, i}
$$

This boiler power is also calculated as a ratio of the maximum power that the boiler can provide:

$$
P_{b o i l, i}=K_{b o i l, i} P_{b o i l, m a x}
$$

It should be noted that a boiler's efficiency depends on its rate of use. For the biomass boiler, efficiency is expressed via Equation (13) with $\mathrm{a}_{\text {biom }}=-0.0014, \mathrm{~b}_{\text {biom }}=0.249$ and 
$c_{\text {biom }}=72.125$ and for the gas boiler via Equation (14) with $\mathrm{a}_{\text {gas }}=-0.045$ and $\mathrm{b}_{\text {gas }}=96.7$, efficiency rates specific to boilers commonly used in France:

$$
\begin{gathered}
\eta_{\text {biom }, i}=-\mathrm{a}_{\text {biom }} K_{\text {biom }, i}^{2}+\mathrm{b}_{\text {biom }} K_{\text {biom }, i}+\mathrm{c}_{\text {biom }} \\
\eta_{\text {gas }, i}=\mathrm{a}_{\text {gas }} K_{\text {gas }, i}+\mathrm{b}_{\text {gas }}
\end{gathered}
$$

For the particular case of biomass boilers, additional constraints (Equations (15) and (16)) are considered $[46,47]$ in order to represent inertia in such a way that does not allow rapid variations in temperature or power or operation below a threshold value $K_{b i o m, t h}$.

Biomass operation is represented in Figure 4, which explains the range of acceptable values for $P_{b i o m, i+1}$ depending on $P_{b i o m, i}$ and $i+1$ period duration. Concerning the inertia influence, $P_{b i o m, i+1}$ can only operate within a determined range of acceptable values defined by $\alpha_{\text {biom rise }}$ and $\alpha_{\text {biom fall }}$. Equations (15) and (16) represent these operating constraints with $\alpha_{\text {biom rise }}=0.22 \mathrm{~kW} / \mathrm{s}$ and $\alpha_{\text {biom fall }}=0.28 \mathrm{~kW} / \mathrm{s}$.

$$
\begin{aligned}
& P_{\text {biom }, i+1} \leq P_{\text {biom }, i}+\alpha_{\text {biom rise }} \Delta t_{i} \\
& P_{\text {biom }, i+1} \geq P_{\text {biom }, i}-\alpha_{\text {biom fall }} \Delta t_{i}
\end{aligned}
$$

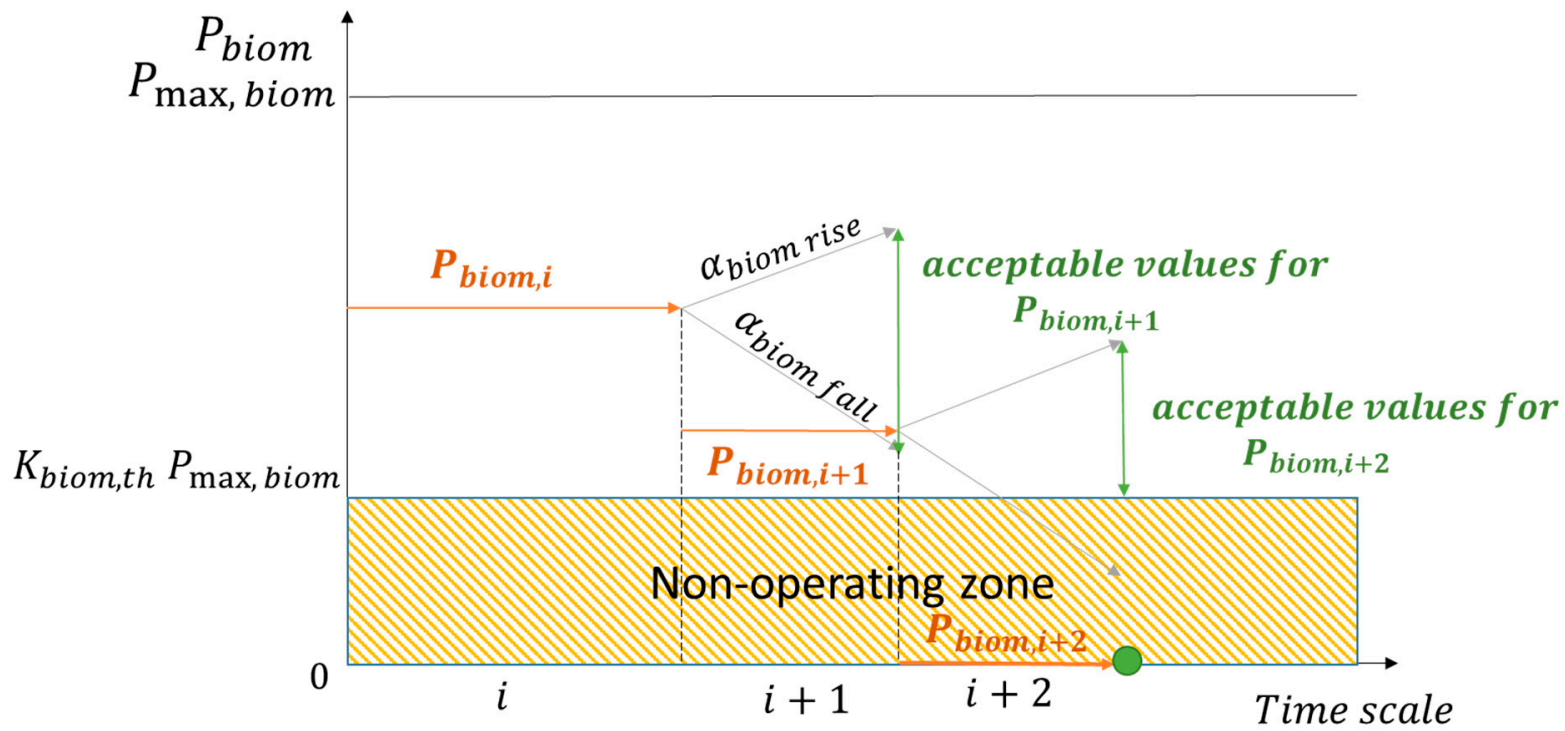

Figure 4. Representation of biomass power as a function of the time step.

For $P_{\text {biom, } i+2}$, if the value is below $K_{\text {biom, th }} P_{\max , \text { biom }}$, it is in the "Non-operating zone" so the value is 0 (here, $K_{b i o m, t h}=0.3$ ). In order to prevent the boiler from operating below $K_{b i o m, t h}$ using a defined, continuous and differentiable formulation, a sigmoid function is used (18). Figure 5 is a representation of the sigmoid function as a function of coefficient $k_{\text {sig }}$ which acts on the slope of the sigmoid. When $x$ is negative, the value of the sigmoid is 0 , and when $x$ is positive, the value is 1 ; we therefore have the equivalent of a binary variable while still retaining a defined, continuous and differentiable formulation. A steep slope gives more reliable results, but the digital complexity is greater (as the derivatives are more difficult to obtain). This function is used in Equation (18) (replacing Equation (12)) to ensure that zero power is supplied to the network when the usage rate is less than the value of $K_{\text {biom,th }}$. The purpose of Equation (19) is to ensure that for values of $k_{\text {sig }}>10$ the sigmoid function does indeed return values of 0 or 1 , depending on the usage rate of the boiler $K_{b i o m, i}$.

$$
\begin{gathered}
\operatorname{sig}(x)=\frac{1}{1+\exp ^{-k_{\text {sig }} x}} \\
P_{\text {biom }, i}=K_{\text {biom }, i} P_{\text {max }, \text { biom }} \operatorname{sig}\left(K_{\text {biom }, i}-K_{\text {biom }, t h}\right)
\end{gathered}
$$




$$
a b s\left(K_{b i o m, i}-K_{b i o m, t h}\right) \geq 0.5
$$

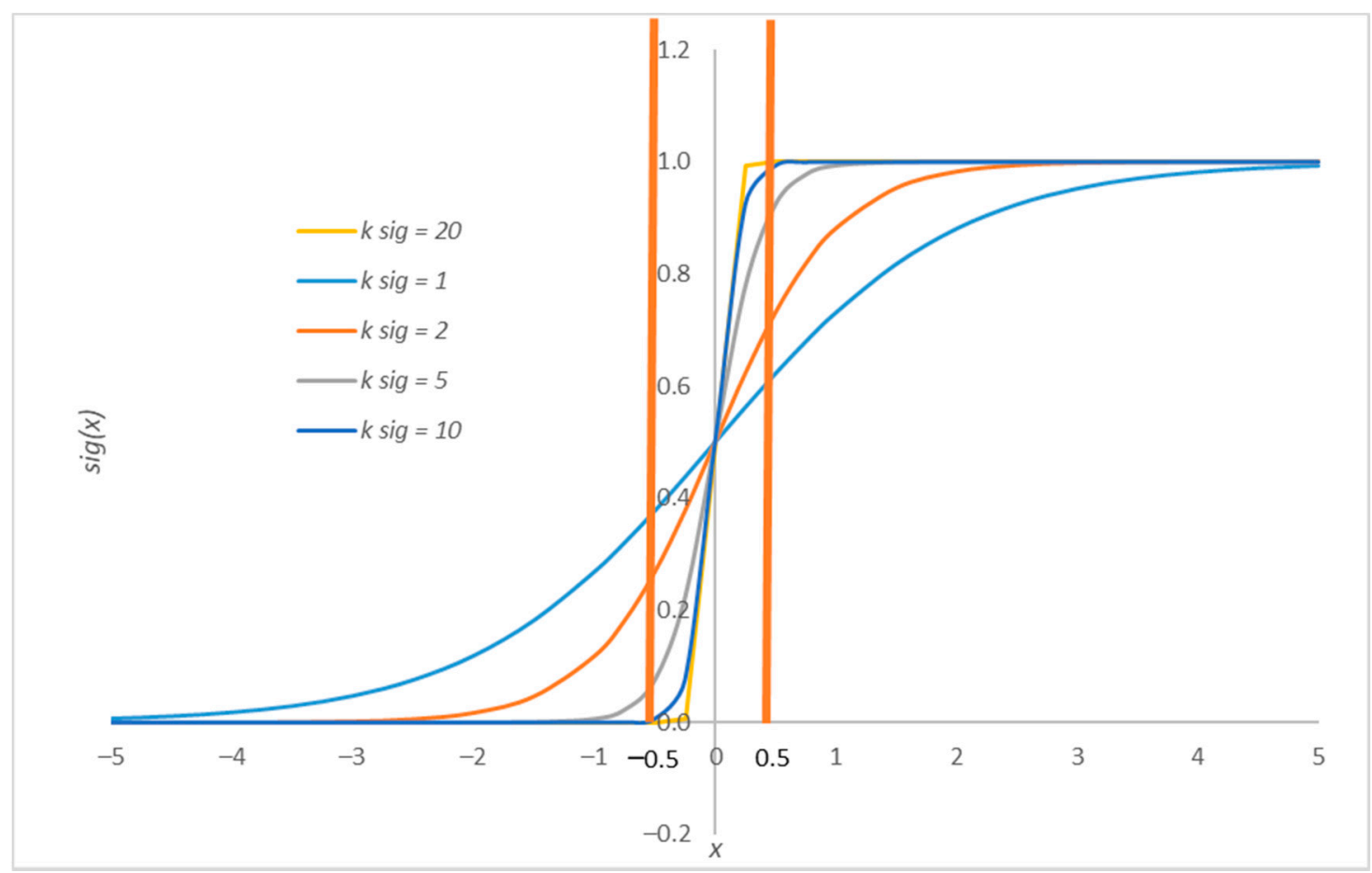

Figure 5. Graph representing a sigmoid function.

\subsection{Storage Model}

The storage model is a total volume divided into two zones (hot and cold) as a thermocline [48] with a constant heat capacity considered at a mean temperature between the hot and cold zones. Each zone is perfectly mixed and cannot exchange heat with the other zone. The storage is connected to the network, as shown in Figure 6, where the flow $\dot{m}_{s t o r, i}$ can be positive or negative, depending on whether the storage is in charge or discharge mode (if $\dot{m}_{\text {stor }, i}>0$ the storage is in charge mode, whereas it is discharging if $\left.\dot{m}_{s t o r, i}<0\right)$. Equations (20)-(22) present mass and energy balances on storage nodes shown in Figure 6.

$$
\dot{m}_{\text {prod }, i}=\dot{m}_{\text {district }, i}+\dot{m}_{\text {stor }, i}
$$

$$
\begin{aligned}
\dot{m}_{\text {district }, i} T_{\text {outward }, i} & =\dot{m}_{\text {prod }, i} T_{\text {out }, \text { prod }, i}-\left(\max \left(\dot{m}_{\text {stor }, i} T_{\text {out }, \text { prod }, i}, 0\right)+\min \left(\dot{m}_{\text {stor }, i} T_{\text {hot }, i}, 0\right)\right) \\
\dot{m}_{\text {prod }, i} T_{\text {in }, \text { prod }, i} & =\dot{m}_{\text {district }, i} T_{\text {return }, i}+\left(\max \left(\dot{m}_{\text {stor }, i} T_{\text {cold }, i}, 0\right)+\min \left(\dot{m}_{\text {stor }, i} T_{\text {return }, i}, 0\right)\right)
\end{aligned}
$$

A sigmoid function (17) is used for a continuously defined and differentiable formulation for both charge and discharge so the energy balance Equations (21) and (22) become the following (23) and (24):

$$
\begin{gathered}
\dot{m}_{\text {district }, i} T_{\text {outward }, i}=T_{\text {out }, \text { prod }, i} \dot{m}_{\text {prod }, i}-\dot{m}_{\text {stor }, i}\left(\operatorname{sig}\left(\dot{m}_{\text {stor }, i}\right) T_{\text {out }, \text { prod }, i}+\left(1-\operatorname{sig}\left(\dot{m}_{\text {stor }, i}\right)\right) T_{\text {hot }, i}\right) \\
\dot{m}_{\text {prod }, i} T_{\text {in }, \text { prod }, i}=T_{\text {return }, i} \dot{m}_{\text {district }, i}+\dot{m}_{\text {stor }, i}\left(T_{\text {cold }, i} \operatorname{sig}\left(\dot{m}_{\text {stor }, i}\right)+\left(1-\operatorname{sig}\left(\dot{m}_{\text {stor }, i}\right)\right) T_{\text {retur }, i}\right)
\end{gathered}
$$

The energy balance per zone results in a differential equation due to the presence of an accumulation term. The finite difference discretization of this differential term links together periods $i$ and $i+1$. A sigmoid function is again used in order to have a single formulation with which to calculate the new temperature level in the hot zone during charging without the temperature of the cold zone being modified (except for losses) and 
vice versa. Equations (25) and (26) present mass balance on each zone and (27) and (28) present energy balances:

$$
\begin{gathered}
V_{\text {hot }, i+1}=V_{\text {hot }, i}+\frac{\dot{m}_{\text {stor }, i}}{\rho} \Delta t_{i} \\
V_{\text {cold }, i+1}=V_{\text {cold }, i}-\frac{\dot{m}_{\text {stor }, i}}{\rho} \Delta t_{i} \\
T_{\text {hot }, i+1}=\left(1-K_{\text {loss }} \Delta t_{i}\right) \cdot\left(T_{\text {hot }, i}\left(1-\operatorname{sig}\left(\dot{m}_{\text {stor }, i}\right)\right)+\operatorname{sig}\left(\dot{m}_{\text {stor }, i}\right) \frac{V_{\text {hot }, i} T_{\text {hot }, i}+\frac{\dot{m}_{\text {stor }, i}}{\rho} \Delta t_{i} T_{\text {out }, \text { prod }, i}}{V_{\text {hot }, i}+\frac{\dot{m}_{\text {stor }, i}}{\rho} \Delta t_{i}}\right) \\
T_{\text {cold }, i+1}=\left(1-K_{\text {loss }} \Delta t_{i}\right) \cdot\left(T_{\text {cold }, i} \operatorname{sig}\left(\dot{m}_{\text {stor }, i}\right)+\left(1-\operatorname{sig}\left(\dot{m}_{\text {stor }, i}\right)\right) \frac{V_{\text {cold }, i} T_{\text {cold }, i}+\frac{\dot{m}_{\text {stor }, i}}{\rho} \Delta t_{i} T_{\text {retur }, i}}{V_{\text {cold }, i}+\frac{\dot{m}_{\text {stor }, i}}{\rho} \Delta t_{i}}\right)
\end{gathered}
$$

with $\Delta t_{i}$ period duration, $K_{\text {loss }}$ thermal storage losses.

The storage considered in this study is the inter-seasonal type. Coupling seasonal storage with characteristic days and the transition between these days has been studied by Kotzur et al. [43] and Heijde et al. [49]. Thus, to represent a typical year with 4 specific days, the state of the storage at the end of the last period (index $n p$ ) must be equal to that at the beginning of the first period (index 0). We therefore have the following volume and temperature constraints: $V_{h o t, 0}=V_{h o t, n p}, V_{\text {cold }, 0}=V_{\text {cold, } n p}$ and $T_{h o t, 0}=T_{h o t, n p}$, $T_{\text {cold }, 0}=T_{\text {cold }, n p}$.

The methodology presented here is adapted to an inter-seasonal model as follows: by considering a year to be 365 days, the typical days method involves considering that each day is repeated 91.25 times and the mid-season day 182.5 times because we choose the same typical day for spring and autumn. The storage is therefore broken down into 91.25 small equal volumes called $V_{\text {part }}$, and we assume that storage use on one of the typical days is the same as for the other 91.25 times. The terms $V_{\text {hot }}$ and $V_{\text {cold }}$ from Equations (26)-(29) become $V_{\text {hot,part }}$ and $V_{\text {cold,part }}$ with $\left(V_{\text {hot,part }}+V_{\text {cold,part }}\right)=V_{\text {part }}$ and $V_{\text {total }}=91.25 \times V_{\text {part }}$. According to Equations (26)-(29), when moving from one typical day to another (i.e., from one season to another) the state of the storage at the end of a season is retained at the start of the next.

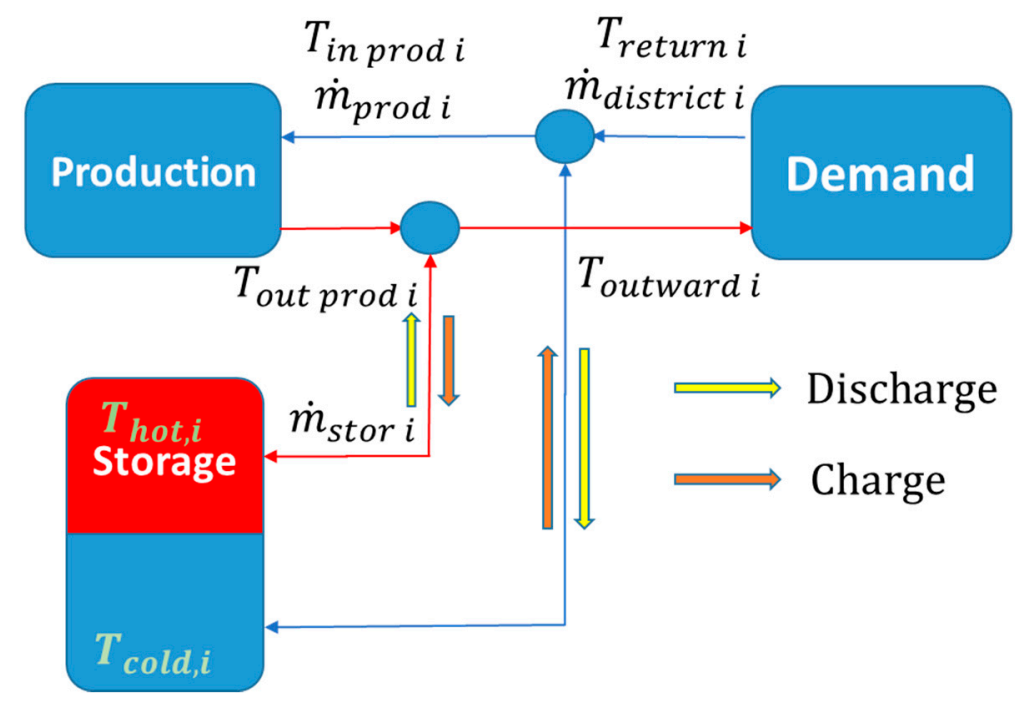

Figure 6. Connection of storage to the network.

\subsection{Economical Model}

In this part, the costs shown take into account aid provided by the French State for a solar heating network giving a renewable energy rate of over $50 \%$. 
As the objective function is economic, the aim was to create functions that are as close as possible to the real data while keeping a formulation that the optimization solver can solve. The reference data were supplied by the various partners of the ISORC project, all specialists in DHNs or solar thermal power plants. In the case of storage costs, for example, 4 types of function were considered in order to approximate real data, as presented in Figure 7, which shows the change in the cost of $\mathrm{m}^{3}$ of storage according to the total storage size. Costs are a function of storage size, and the proposed function considers values representing different types of technologies, from water tanks for smaller sizes to pit storage for larger ones.

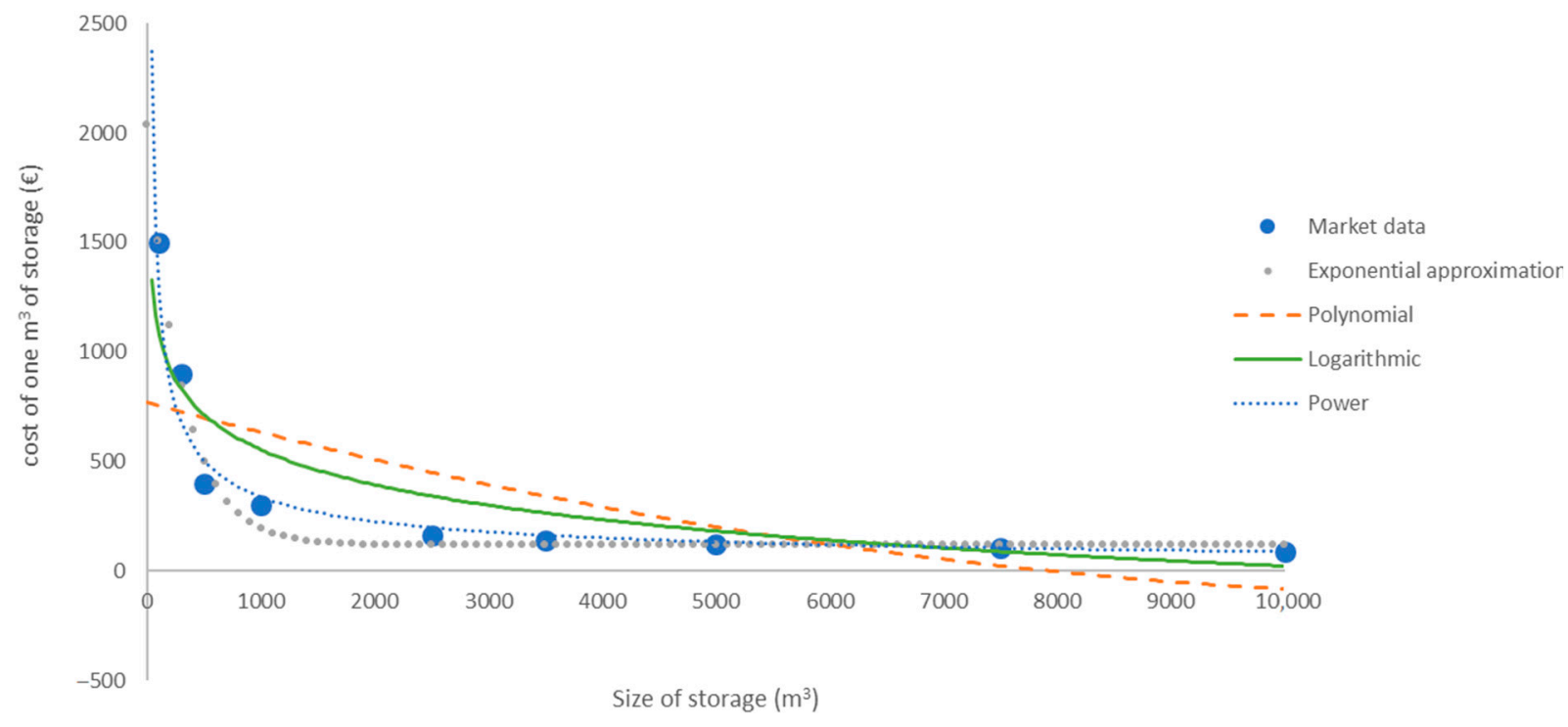

Figure 7. Approximation of market data with different approaches.

The Figure 7 is also an example of the relevance of the choice of a nonlinear formulation for our optimization problem. The approximate functions are the following (Equations (29)-(32)), with $a_{\text {stor }}, b_{\text {stor }}$ and $c_{\text {stor }}$ the function coefficients:

$$
\begin{gathered}
\text { polynomial CapEx } \operatorname{stor}=\left(a_{\text {stor }} V_{\text {stor }}^{2}+b_{\text {stor }} V_{\text {stor }}+c_{\text {stor }}\right) V_{\text {stor }} \\
\text { logarithmic CapEx } \operatorname{stor}_{\text {stor }}=\left(a_{\text {stor }} \log \left(V_{\text {stor }}\right)+b_{\text {stor }}\right) V_{\text {stor }} \\
\text { exponential CapEx }{ }_{\text {stor }}=\left(a_{\text {stor }} \exp \left(-\frac{V_{\text {stor }}}{b_{\text {stor }}}\right)+c_{\text {stor }}\right) V_{\text {stor }} \\
\text { power CapEx } \text { stor }=\left(a_{\text {stor }} V_{\text {stor }} b_{\text {stor }}\right) V_{\text {stor }}
\end{gathered}
$$

Different tests were carried out before ultimately choosing the exponential approach (31) $\left(a_{\text {stor }}=\operatorname{EUR} 1918.45 / \mathrm{m}^{3}, b_{\text {stor }}=309.77 \mathrm{~m}^{3}\right.$ and $\left.c_{\text {stor }}=E U R 117.62 / \mathrm{m}^{3}\right)$ to calculate the installation costs (CapEx) while keeping a reasonable degree of precision, as can be seen in Figure 7. The exponential approach has the advantage of being able to take into account storage larger than $10,000 \mathrm{~m}^{3}$ because the costs converge to the value of $c_{\text {stor }}$. This same approach is also used for modeling solar costs represented by Equation (33) with $a_{\text {sol }}=\operatorname{EUR} 572.64 / \mathrm{m}^{2}, b_{\text {sol }}=4069 \mathrm{~m}^{2}$ and $c_{\text {sol }}=E U R 216.5 / \mathrm{m}^{2}$ :

$$
\operatorname{CapEx}_{\text {sol }}=\left(a_{\text {sol }} \exp \left(-\frac{S_{\text {sol }}}{b_{\text {sol }}}\right)+c_{\text {sol }}\right) S_{\text {sol }}
$$

Storage operation costs and pumping costs for the entire network were assumed to be zero as they are negligible compared to the other operating costs which are presented 
below (usually representing less than $1 \%$ of the total costs [1]). Concerning the operating costs for the boilers and the solar plant, they were broken down as follows:

First the operating costs OpEx were broken down into 3 parts:

- The first part (Equation (34)) covers the use of fuels across all time periods. The cost per unit fuel cost $t_{x}$ can vary every year depending on scenarios (here they are constant: $f$ uel cost biom $=$ EUR 27.5/MWhLHV, fuel cost $t_{\text {gas }}=E U R$ 40/MWhHHV); $n b y$ is the lifespan of the installation. This cost is zero in the case of solar:

$$
\text { OPEX P1 } 1_{b o i l}=\sum_{y=1}^{n b y} \sum_{k=1}^{3} \operatorname{Seas}_{k} \sum_{i=1}^{24} f u e l \operatorname{cost}_{b o i l, y} \cdot P_{b o i l, k, i} \cdot \Delta i
$$

- The second part of the operating costs covers light maintenance. This is expressed by Equations (35)-(37) with $a_{p 2, b i o m}=$ EUR $3 / \mathrm{kWh}^{2}, b_{p 2, \text { biom }}=$ EUR 10,000/h, $a_{p 2, g a s}=$ EUR $4200 / \mathrm{kWh}, b_{p 2, g a s}=$ EUR $7000 / \mathrm{h}$ and $a_{p 2, s o l}=0.04 \mathrm{~h}^{-1}$ :

$$
\begin{gathered}
\text { OpEx } P 2_{\text {biom }}=\text { lifespan }\left(a_{p 2, \text { biom }} \sum_{i=1}^{n p}\left(P_{b i o m, i} \cdot \Delta i\right)+b_{p 2, \text { biom }}\right) \\
\text { OpEx } P 2_{\text {gas }}=\text { lifespan }\left(a_{p 2, \text { gas }} P_{g a s, m a x}+b_{p 2, g a s}\right) \\
\text { OpEx } P 2_{\text {sol }}=\text { lifespan }\left(a_{p 2, \text { sol }} \text { CapE } x_{\text {sol }}\right)
\end{gathered}
$$

- The last part of the operating costs covers heavy maintenance, which depends on the size of the installation, represented here by CapEx $\left(a_{p 3, b i o m}=0.015 \mathrm{~h}^{-1}\right.$, $a_{p 3, g a s}=0.02 \mathrm{~h}^{-1}$ and $a_{p 3, s o l}=0.017 \mathrm{~h}^{-1}$ ):

$$
\begin{aligned}
\text { OpEx } P 3_{\text {boil }} & =\text { lifespan } a_{p 3, \text { boil }} \text { CapEx } x_{\text {boil }} \\
\text { OpEx } P 3_{\text {sol }} & =\text { lifespan } a_{p 3, s o l} \text { CapEx } x_{\text {sol }}
\end{aligned}
$$

CapEx is calculated from Equation (40) $\left(a_{\text {capex,biom }}=\right.$ EUR $629.179 / \mathrm{kW}, b_{\text {capex }, \text { biom }}=$ EUR $1,250,716, c_{\text {capex }, \text { biom }}=0.55, a_{\text {capex }, \text { gas }}=$ EUR $105.44 / \mathrm{kW}, b_{\text {capex }, \text { gas }}=$ EUR 549, 397 and $c_{\text {capex,gas }}=1$ ):

$$
\text { CapEx }_{\text {boil }}=\left(a_{\text {capex,boil }} P_{\text {boil,max }}+b_{\text {capex,boil }}\right) c_{\text {capex,boil }}
$$

Finally, the objective function of the optimization problem is written as the sum of all operational expenditures and capital expenditures (41). This function minimizes the costs while taking into consideration the physical constraints from (4)-(29):

$$
\begin{aligned}
& \text { Objective }=\min \left(\mathrm{CapEx}_{\text {sol }}+\mathrm{OpEx} P 2_{\text {sol }}+\mathrm{OpEx} P 3_{\text {sol }}+\mathrm{CapEx}_{\text {stor }}+\mathrm{OpEx} P 1_{\text {biom }}+\mathrm{OpEx} P 2_{\text {biom }}\right. \\
& \left.+\mathrm{OpEx} P 3_{\text {biom }}+\mathrm{CapEx}_{\text {biom }}+\mathrm{OpEx} P 1_{\text {gas }}+\mathrm{OpEx} P 2_{\text {gas }}+\mathrm{OpEx} P 3_{\text {gas }}+\mathrm{CapEx}_{\text {gas }}\right)
\end{aligned}
$$

\subsection{Resolution Strategy}

In contrast to MILP optimization problems, which are often used in the literature for this kind of study, NLP allows nonlinear constraints, thus giving better modeling of physical or economical phenomena. However, there is no guarantee that the solution of an NLP problem will converge, and if it does, there is doubt as to whether it converges towards the global optimum (compared to LP problems). This is why a methodology is required in order to introduce and initialize the complete model gradually, as shown in Figure 8, to obtain a confident solution as Marty et al. have done in [11]. 


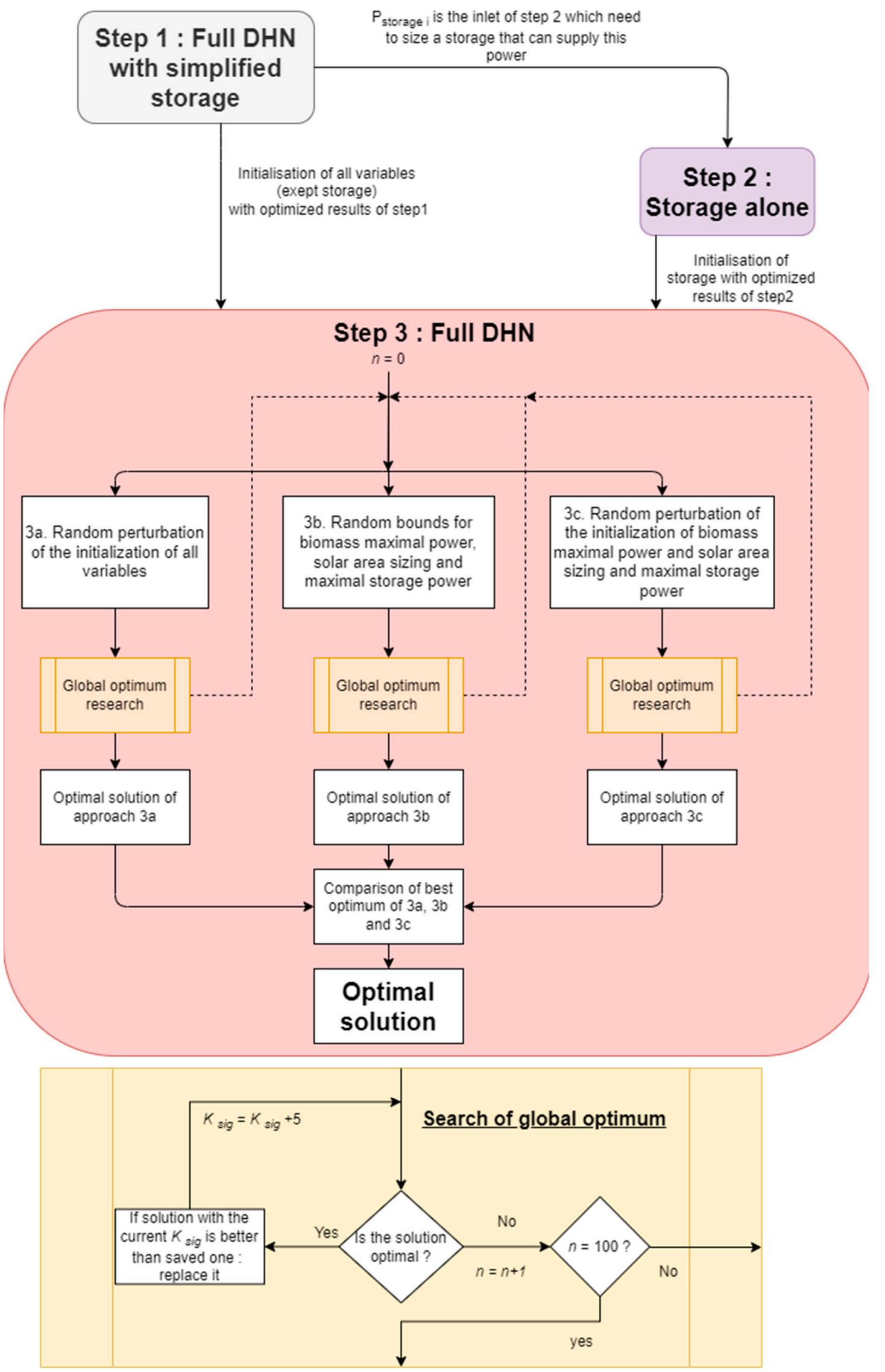

Figure 8. Schematic diagram of the initialization and resolution strategy to reach a reliable optimum. 
Starting from a simplified model ensuring rapid convergence (Figure 9), several sequential optimization steps were initialized with the optimum results from the previous steps, which gradually complexified the model until the final model was achieved with the desired complexity (Figure 8).

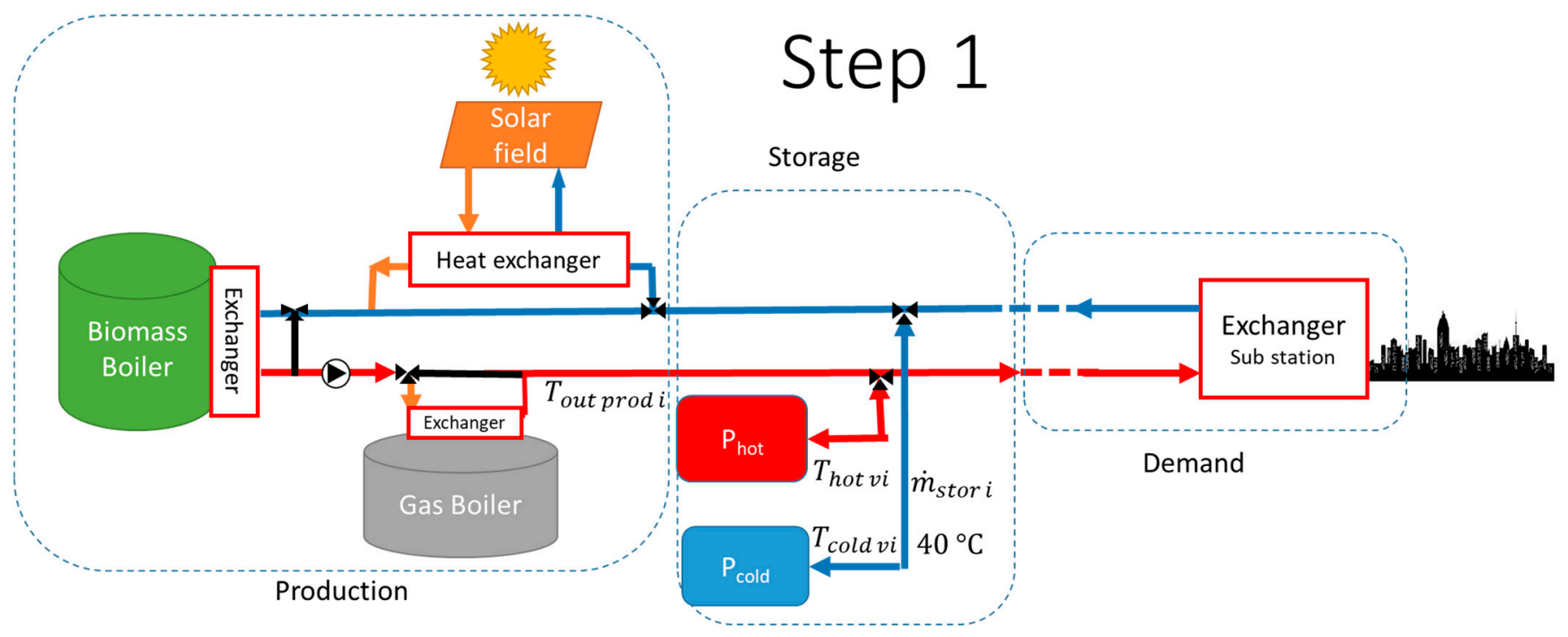

Figure 9. Step 1: Full DHN with simplified storage model.

In this approach, shown schematically in Figure 8, the objective function is still economic, and the first step takes into account the system as a whole for the production part but considers a simplified model to represent storage (Figure 9). The aim is to initialize the flows and the power provided by the storage, with sizing being free of charge (in order to start from a solution promoting the use of solar energy and storage). The hot branch $T_{\text {hot } v, i}$ takes either the production output value $T_{\text {out }, \text { prod, } i}$ when charging $\left(\dot{m}_{\text {stor }, i}>0\right.$ and $\left.P_{\text {stock }, i}<0\right)$ or the fixed value of $80{ }^{\circ} \mathrm{C}$ when discharging $\left(\dot{m}_{\text {stor }, i}<0\right.$ and $\left.P_{\text {stock }, i}>0\right)$ according to Equation (42). The cold branch $T_{\text {cold } v, i}$ has a constant value set at $40{ }^{\circ} \mathrm{C}$ (Equation (43)) as there is little variation in temperature in the cold branch. Equation (43) calculates storage power, which may be positive or negative depending on the value of the flow.

$$
\begin{gathered}
T_{\text {hot } v, i}=\operatorname{sig}\left(\dot{m}_{\text {stor }, i}\right) T_{\text {out }, \text { prod }, i}+\left(1-\operatorname{sig}\left(\dot{m}_{\text {stor }, i}\right)\right) \times 80{ }^{\circ} \mathrm{C} \\
T_{\text {cold } v, i}=40{ }^{\circ} \mathrm{C} \\
P_{\text {stor }, i}=-C p \dot{m}_{\text {stor }, i}\left(T_{\text {hot } v, i}-T_{\text {cold } v, i}\right)
\end{gathered}
$$

The additional Equation (45) ensures that over a typical year, inter-seasonal storage does indeed have a storage/loss of storage energy balance of zero:

$$
\sum_{i=1}^{n p} P_{\text {stor }, i}=0
$$

Thus, using this first approach gives an initial sizing of the production site promoting the use of storage, which also tends to favor the use of the solar heat plant.

Secondly, storage alone is optimized to show optimum sizing for storage capable of supplying the power for storage/loss of storage $P_{\text {stor }, i}$ calculated in step 1.

Once these two steps have converged, the results of these optimizations are used to initialize step 3 which uses the full model. Using this 3-step sequence, the full model can be converged. Next it is necessary to ensure that optimum confidence is obtained. 
For this reason, step 3 is itself broken down into 3 parts, which use different approaches to obtain a set of optimum solutions (often the same) in order to choose the best. These three approaches carry out the following:

a. Random perturbation to the initialization of all the variables.

b. Random perturbation to the bounds of the 3 most sensitive variables:

- Lower bound of the maximum power of the biomass boiler.

- Lower bound of the surface area of the solar field.

- Lower bound of the power that the storage can supply.

c. Random perturbation to the initialization of these same 3 sensitive variables.

Concerning the sigmoid functions used to operate the biomass boiler and storage Equations (23) and (24), optimizations were carried out with an initial data slope for $k_{\text {sig }}=10$, and, in the event of convergence, a new optimization was carried out using the same initialization but this time with a greater slope (i.e., with $k_{\text {sig }}$ increased by 5 ). It was thus possible to converge towards the example with the greatest possible slope and hence towards an operation that corresponds best to reality.

\subsection{Julia (JuMP)}

The open-source Julia programming language [12] was selected for its fast computation and its optimization package JuMP. With this package, different optimization solvers are used while keeping the same formulation. Therefore, a different complexity for the system to be optimized can be resolved with open-source Ipopt or commercial Knitro NLP solvers. In this study, optimization was carried out with the open-source Ipopt solver as the final optimization tool must be open-access.

\section{Case Study}

The tool for which the methodology is presented above was applied to the case of a low-temperature $\left(60{ }^{\circ} \mathrm{C}\right.$ outward $/ 40{ }^{\circ} \mathrm{C}$ return) DHN located in the south of France considering a global DHN demand and climate of this region. Optimization was conducted over one year using four typical days (winter, mid-season, summer and mid-season). Demand $(\mathrm{kW})$, external temperature $\left({ }^{\circ} \mathrm{C}\right)$ and global irradiance $\mathrm{G}\left(\mathrm{W} / \mathrm{m}^{2}\right)$ of these 3 days are presented in Figure 10. The characteristic profiles of these days are obtained by using the minimizations presented in Equation (41).

For this case study, sizing variables are solar field area $A_{\text {sol, }}$ maximum storage volume $V_{\text {tot }}$ and maximum power for the biomass boiler $P_{\max , b i o m}$. Relevant operation variables are mass flow rates: $\dot{m}_{\text {prod }, i}, \dot{m}_{\text {district }, i}, \dot{m}_{\text {stor }, i}$, and transferred power $P_{\text {biom, }, \text { rod }, i}, P_{\text {gas }, \text { prod }, i}, P_{\text {stor }, i}$ and $P_{\text {sol, } i}$.

It was stated previously that for each period demand had to be satisfied (Equation (5)). In addition, for safety reasons and in order to ensure the supply of heat to consumers, the maximum power of the gas boiler is sized so that it is able to meet maximum demand on its own. This sizing is commonly used for DHNs in France, and consequences are discussed in part 4 . The sizing variable $P_{g a s, \max }$ thus becomes a written datum such that $P_{\text {gas, } \max }=\max _{i} P_{\text {demand } i}$. 


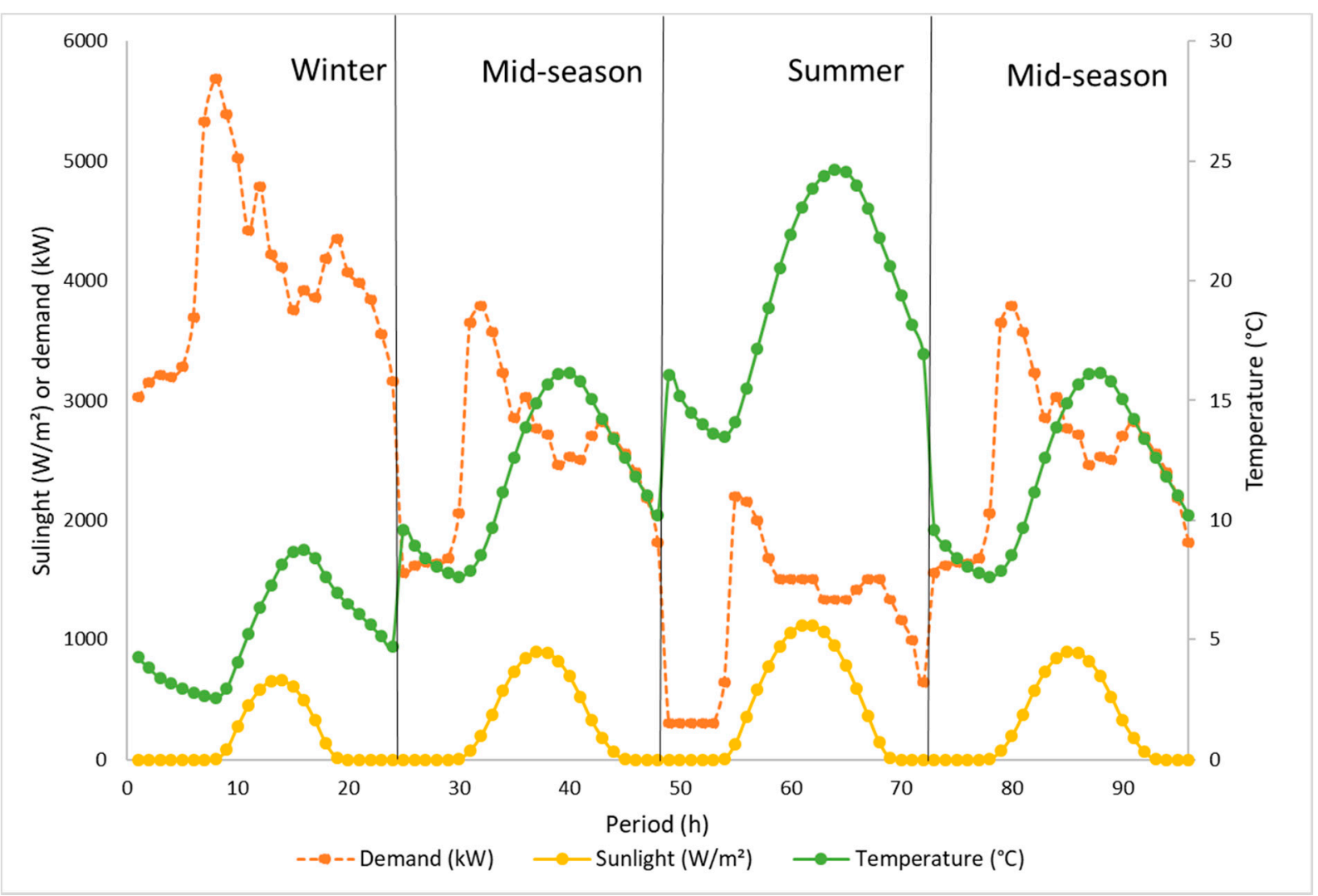

Figure 10. Profile of the three typical days: winter-mid-season-summer.

\section{Results and Discussion}

Optimization was carried out to minimize total cost, as expressed in Equation (41) over a period of 20 years ( $n b y=20$, fuel costs per unit are constants) with one year represented by four typical days. It is essential to consider costs over the long term because, depending on the type of production unit, the proportion of CapEx compared to OpEx can vary considerably. Those production units (solar + storage) where costs are due mainly to installation (CapEx) are compared to those (gas and biomass) where operational costs $(\mathrm{OpEx})$ represent a major share. First, the advantage of the resolution methodology is shown, then the results of the optimizations are given.

\subsection{Results of the Resolution Strategy}

Table 1 shows the results for optimal sizing for each approach. We note that approach $\mathrm{b}$ converges for the steepest sigmoid slope. It is also the approach which finds the best optimum (for the value of $\left.\mathrm{k}_{\mathrm{sig}}=10\right)$. Differences between the approaches are small $(2-3 \%)$.

Table 1. Optimal configuration for each approach for step 3.

\begin{tabular}{ccccc}
\hline Approach & Solar Area $\left.\mathbf{( m}^{\mathbf{2}}\right)$ & Storage Size $\left.\mathbf{( m}^{\mathbf{3}}\right)$ & $\boldsymbol{P}_{\text {biomass, } \max } \mathbf{( k W )}$ & Total Costs $($ Million EUR) \\
\hline a & 5707 & 20,068 & 2265 & 24.931 \\
b & 7749 & 35,006 & 1137 & 24.811 \\
c & 4500 & 12,159 & 2221 & 25.333 \\
\hline
\end{tabular}

Table 2 enhances these results by giving the confidence that can be placed in the results from the number of optimizations that converged for each approach. Approaches a and $c$ had more difficulty in obtaining convergence $(<5 \%$ of the time) and remained close to the average result (standard deviation $\sim 0.065$ ), while convergence with approach $b$ was more reliable $(20 \%)$ but resulted in a higher total average cost than the other approaches 
(standard deviation $\sim 0.56$ ). This means that it often obtains a local optimum. Concerning solar coverage, it reaches $45 \%$ of the supplied heat with approach $\mathrm{b}$, while it covers $34 \%$ for approach a and 20\% for approach c. Calculation times are around $3 \mathrm{~h} 50 \mathrm{~min}$ which is important for this kind of tool. However, it includes the runs of the three steps especially the $3 \times 100$ optimizations, although solving the problem one time takes around $2 \mathrm{~min}$.

Table 2. Computational results and convergence analysis.

\begin{tabular}{ccccc}
\hline Approach & Convergence (\%) & Average Total Costs (Million EUR) & Standard Deviation & Calculation Time \\
\hline $\mathrm{a}$ & 3 & 25.040 & 0.0770 & $3 \mathrm{~h} 43 \mathrm{~min}$ \\
$\mathrm{~b}$ & 20 & 25.759 & 0.5611 & $3 \mathrm{~h} 49 \mathrm{~min}$ \\
$\mathrm{c}$ & 5 & 25.420 & 0.0627 & $3 \mathrm{~h} 48 \mathrm{~min}$ \\
\hline
\end{tabular}

Figure 11 is a graphic representation of the distribution of optimal power supplied during each period. Only the storage power can be negative, which corresponds to periods when energy is stored, and conversely, during phases of loss of storage, this power is positive. The different heat production sources have their specific operating mode for each season. The gas boiler is operational for almost the entire winter and the beginning of spring but only rarely during the rest of the year. In winter, the gas boiler power is reduced in some periods, when either the storage or the solar field can make up for this decline in power. The biomass boiler operates at its maximum power throughout the winter and in early spring, then operates at low power for the rest of the year. It stops completely during periods when sunlight is at its maximum and solar can meet demand on its own. Storage is sized according to the solar heat, and must be able to store the power supplied during the sunniest period, i.e., the 63rd period. With storage in place, production can be adjusted, especially from spring onwards, and thus the gas boiler is turned off as much as possible in favor of using solar then biomass power.

There are a few periods when the gas boiler produces more power than is needed to supply demand and this is intended for storage. This is because among all the possible operational solutions, some are identical. There is a need to store power in winter so that the storage can take over from gas in satisfying demand in the other seasons. The gas boiler is more efficient when its usage rate is high, and in addition, the cost of using stored power is zero (no pumping costs), and thus energy is stored in the form of available energy which will be utilized in later periods. The gas boiler power is therefore greater than demand in one of the periods in order to anticipate its use in the periods that follow.

\subsection{Study of Different Storage Connections}

Three different types of storage connection are shown in Figure 12. The cold zone is always connected to the return pipe from the consumers, while the study covers different connections for the hot pipe:

The optimum results for these different configurations are summarized in Table 3, which shows the values of the different optimum sizing variables according to the hot storage volume connections: Operational costs are obtained by multiplying the operational costs for a typical day by the number of times this is repeated. We therefore see that the minimum cost over 20 years is EUR 24.348 million for an outlet pipe from the solar field (configuration 1) when approach " $b$ " is used for the resolution strategy. This is the same approach that gives the optimum result for connection 3 (gas outlet). 


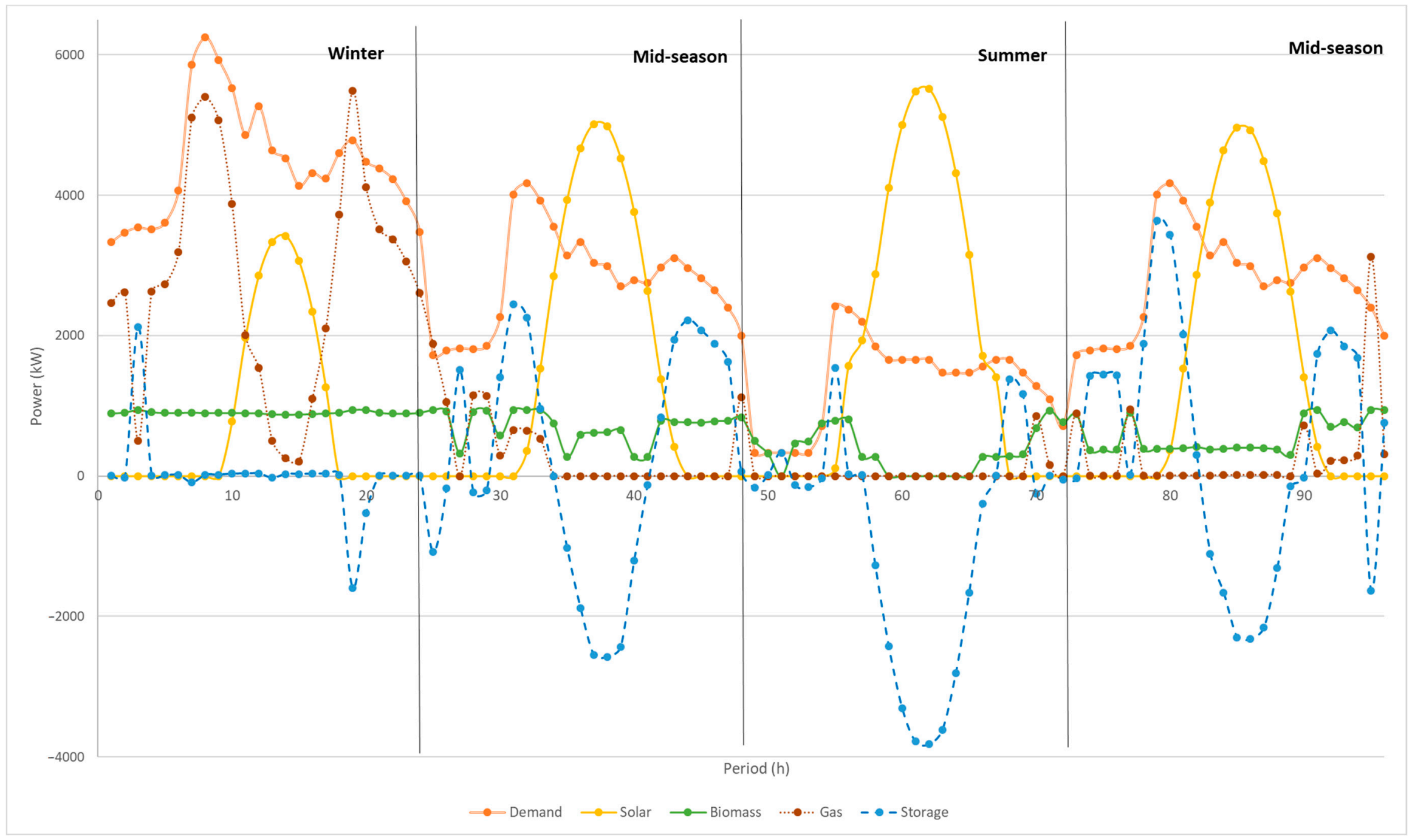

Figure 11. Optimal power operation for model presented in methodology for approach $b$. 


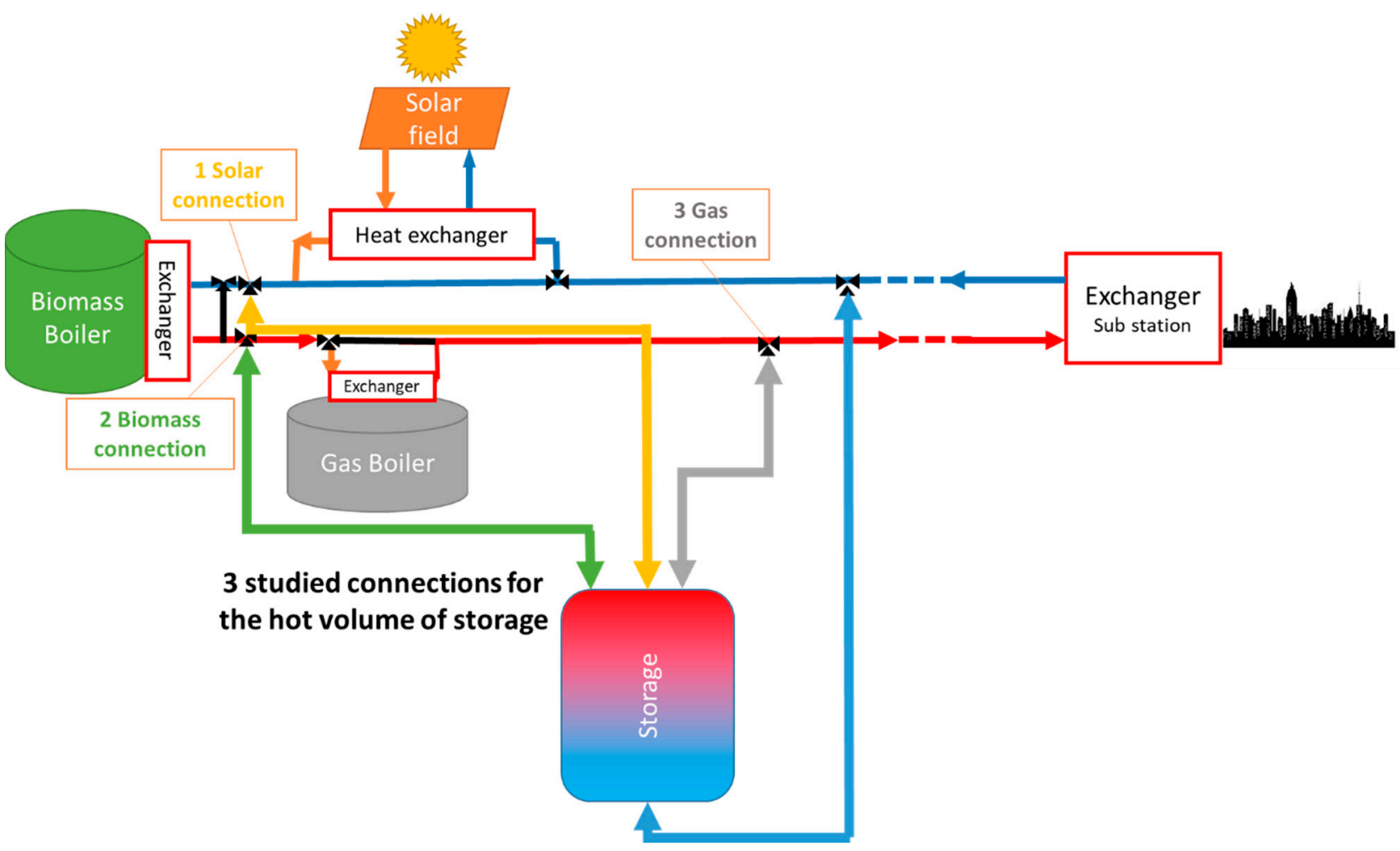

Figure 12. Study diagram, comparing different connections for hot storage volume (yellow = solar connection, green $=$ biomass connection, grey $=$ gas connection) .

Table 3. Optimal configuration for each connection studied.

\begin{tabular}{cccccc}
\hline Connection & Approach and $\boldsymbol{k}_{\text {sig }}$ Value & Total Costs (Million EUR) & $\boldsymbol{S}_{\text {sol }}\left(\boldsymbol{m}^{2}\right)$ & $\boldsymbol{P}_{\text {biomass, max }}(\boldsymbol{k W})$ & $\boldsymbol{V}_{\text {total }}\left(\boldsymbol{m}^{3}\right)$ \\
\hline 1-Solar & b. 10 & 24.348 & 7812 & 916.3 & 35,209 \\
2-Biomass & a. 10 & 24.975 & 6576 & 983.7 & 26,516 \\
3-Gas & b. 10 & 24.811 & 7749 & 1137 & 35,006 \\
\hline
\end{tabular}

Regarding connection 2 (biomass outlet), it can be seen that the optimum is obtained by using the "a" approach, although this approach converges less frequently. This result therefore justifies the choice of resolution with approach "a" because even though it performed less well in terms of convergence, it provided an optimum that approach " $b$ " was not able to obtain. We observe that the total costs varied by $2.51 \%$ between connections 1 and 2, the solar surface area by $15.82 \%$ and the biomass boiler by $19.43 \%$. It is in the storage volume that we can see the most significant difference, as much as $25 \%$. One explanation for the optimum obtained with the storage connected to the solar outlet is that the temperature at the solar field outlet is always lower than or equal to that at the gas boiler outlet (see Figures 13 and 14), and therefore it is easier to use the stored heat without risking lowering the temperature level. This is why configuration 1 is better than configuration 3; the temperature at the solar field outlet is always lower than or equal to that at the gas boiler outlet. In Figures 13 and 14, it can be clearly seen that for connection 1 , it is easier to use the storage as the temperatures are much lower than for connection 3 , linked up to the gas boiler outlet. 


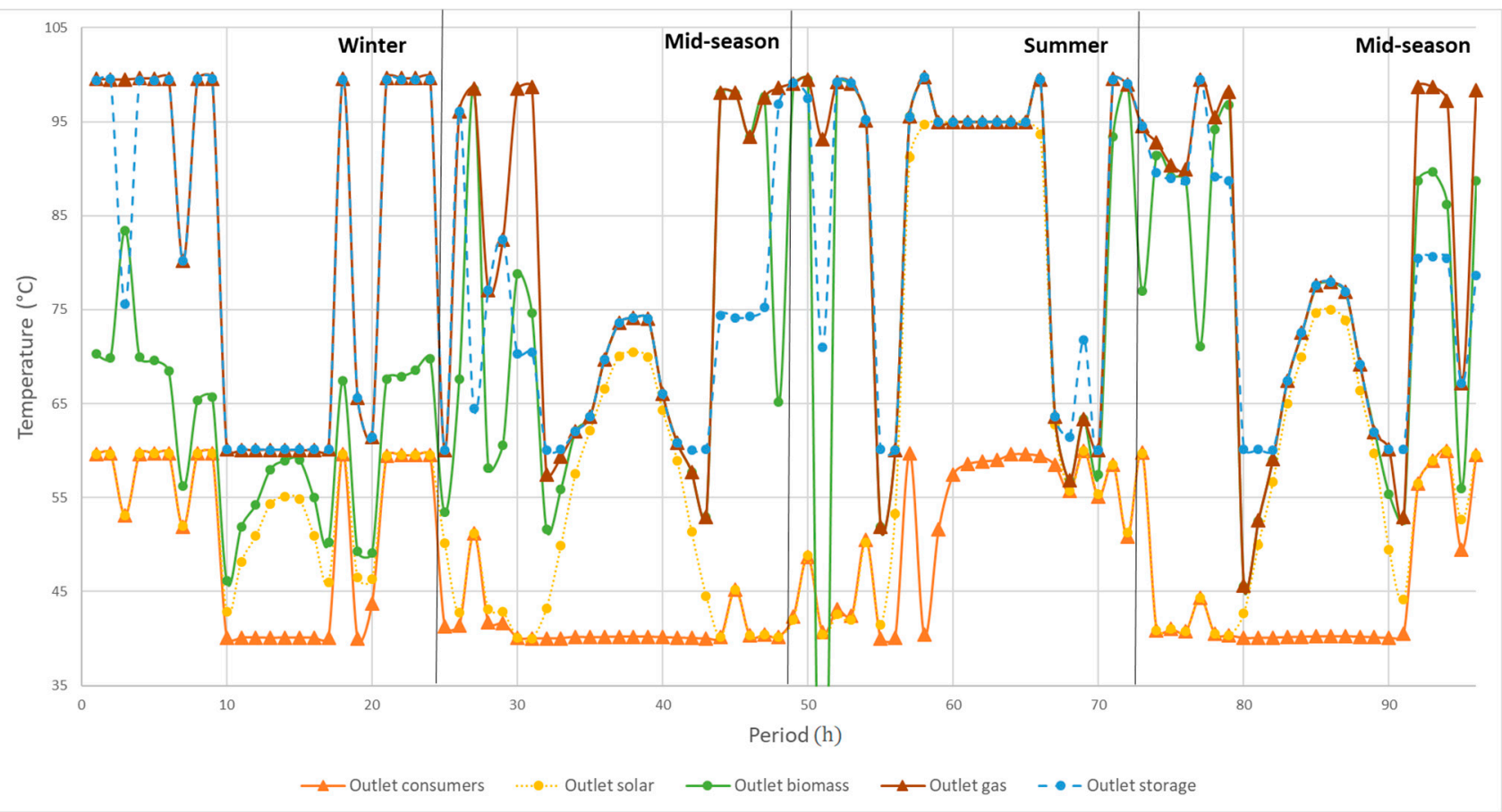

Figure 13. Temperature at different points of the DHN (connection 3).

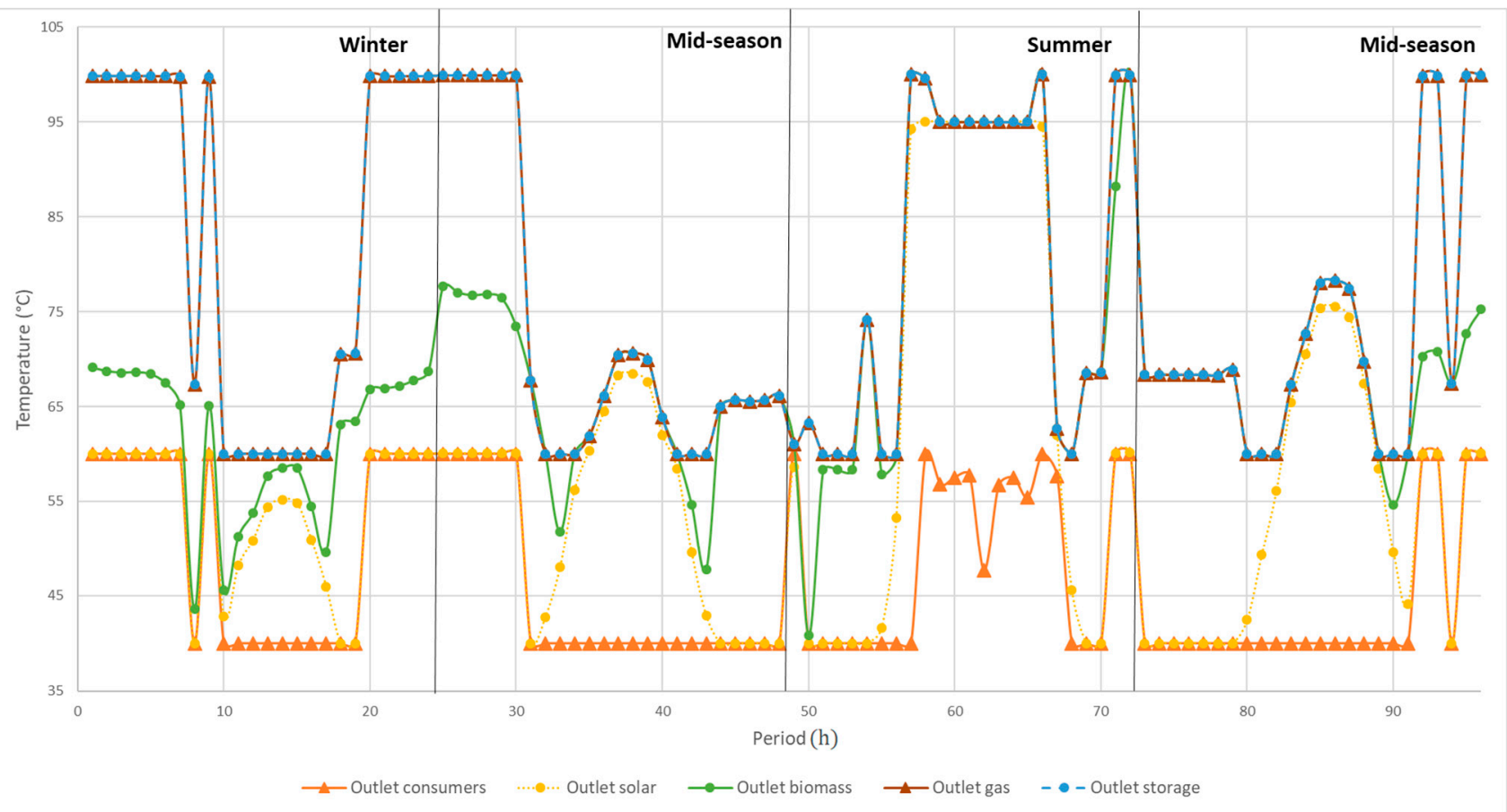

Figure 14. Temperature at different points of the DHN (connection 1).

Concerning storage size, the volume is about 5-10 times larger than the SDHNs identified on SDH.eu [50]. An upper bound was added to the storage, and the new optimal results converged to a solution $3.78 \%$ more expensive with $24 \%$ solar and $56 \%$ biomass coverage (the usual sizing that can be found in [50]). This application case could confirm that using the optimization tool could at the same time improve solar rate in DHNs and reduce costs. 
Figure 15 shows, for the best storage connection (1), the power supplied by the different installations in response to demand for each period. First, we note that the operation of the biomass boiler is similar to that observed in Figure 11; power is usually at its maximum, and for a few periods its operational function declines in order to reduce the use of the gas boiler (more expensive). Moreover, Table 3 shows that total costs are lowest when maximum power for the biomass boiler is at its lowest and storage volume and solar field surface area are at their largest.

In winter, the three production sources together ensure that demand is met: Biomass and solar produce heat at their maximum level. The gas boiler and the storage provide the shortfall in power at each period.

From spring onwards, power supplied by the solar field in the middle of the day is greater than demand. Surplus power can thus be stored when there is a lot of sunshine and drawn off when there is a lack of power during less sunny periods. By operating in this way, there is almost no longer any need to use the gas boiler; from spring onwards, it is only brought into operation to make up for small differences between demand and production. It can be seen that in this configuration the gas boiler power is never greater than the demand as it happened twice in Figure 11.

During peak periods of sunshine, temperatures may be high, and therefore heat storage can be replenished. Maximum power levels in the solar field and storage are greater than those for Figure 11, which means that it is possible not to resort to gas during certain periods, as can be seen from the sizing of sources in Table 3. These variations in temperature are shown in Figure 14, which presents temperature levels at different points of the network according to the period. Periods when the temperature at the solar outlet is equal to that at the gas boiler outlet correspond to the periods when solar is able to meet demand on its own and can even store excess power to inlet consumers.

Let us now turn to an analysis of the "technical-economic" results. Figure 16 shows the distribution of energy supplied throughout the total lifespan of the installation in percentages. We note that the renewable energy rate (solar + biomass) is $69 \%$ (use of the economic model based on a network with a renewable energy rate higher than $50 \%$ is therefore justified). Next, Figure 17 shows the percentage of total costs that correspond to each item of expenditure. By analyzing these two figures together, we observe that the solar-storage couple represents $37 \%$ of total investment costs, ultimately providing $49 \%$ of the total energy produced. The biomass boiler represents $23 \%$ of investment costs (OpEx + CapEx) to supply 20\% of total energy. Finally, the gas boiler represents $40 \%$ of investment costs and only $31 \%$ of the energy supplied. This clearly highlights the relevance of a heating network powered by solar. It is important to remember that the gas boiler is still indispensable because during the winter it is the only source that can ensure that demand is met (Figure 15). Added to this is the sizing constraint linked to supply needs, with the result that the gas boiler is oversized by $18 \%$ compared to the maximum power that it supplies on its average days. This involves an increase in costs of EUR 400,000. The biomass boiler acts as a buffer, meeting demand at the lowest cost (compared to gas) during periods when the solar resource is not available. The optimum obtained therefore corresponds to the sizing and operation of these sources (with storage), minimizing costs over a period of 20 years.

Over this period, the cost of the heat obtained is EUR 54.00/MWh, which makes it competitive given the price of heat in networks in major French cities (Paris, EUR 60/MWh, Lyon EUR 85/MWh [1]).

This study has therefore enabled us to analyze the optimal sizing and operation of a heating network powered by three sources (solar, biomass and gas). The sizing is such that solar can fully meet demand for many periods and also store excess heat. Thus, with the inter-seasonal storage model, heat stored in summer can be used in winter in order to optimize the use of solar energy. 


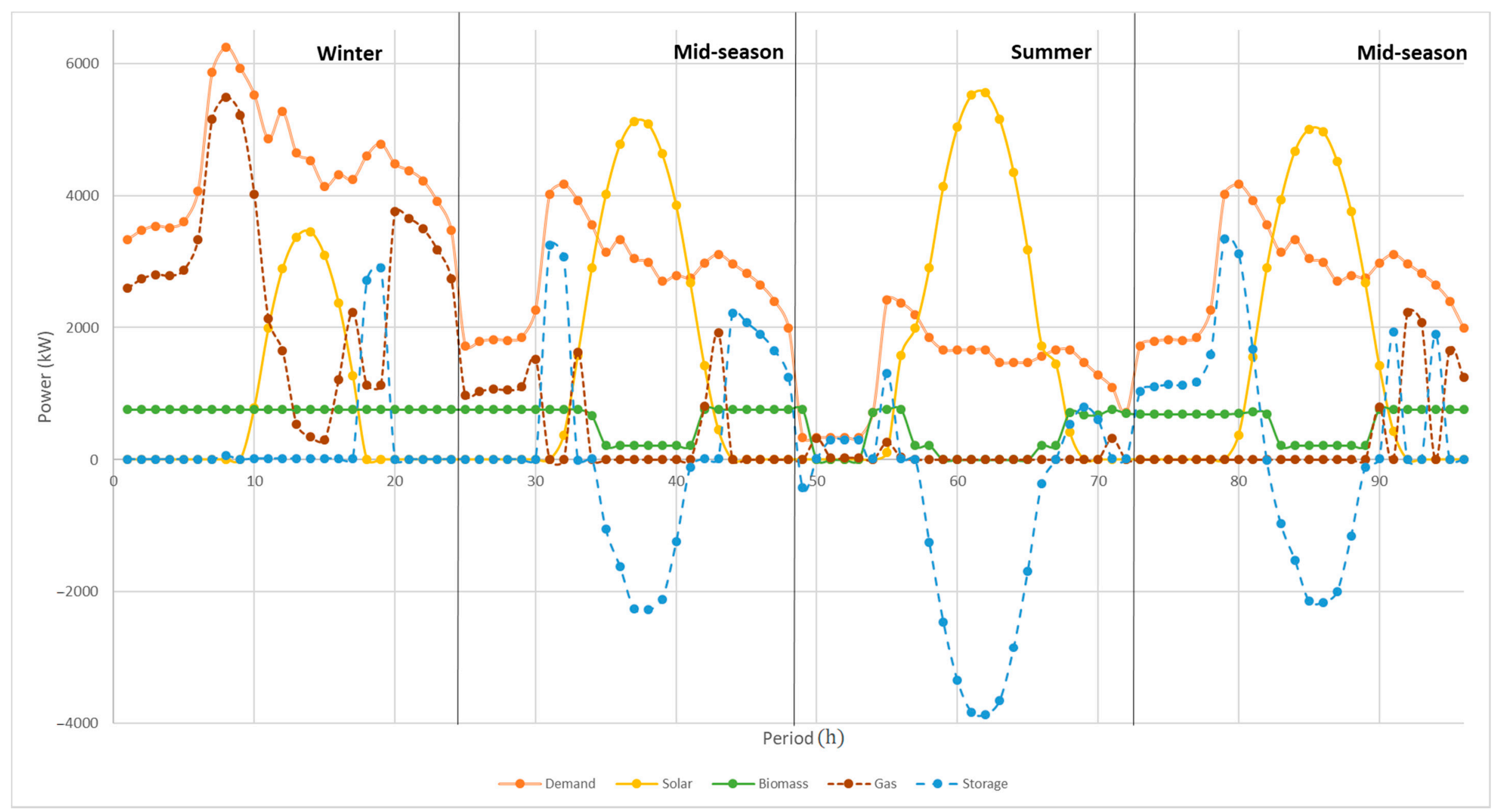

Figure 15. Optimal power operation for storage connected after solar field (connection 1). 


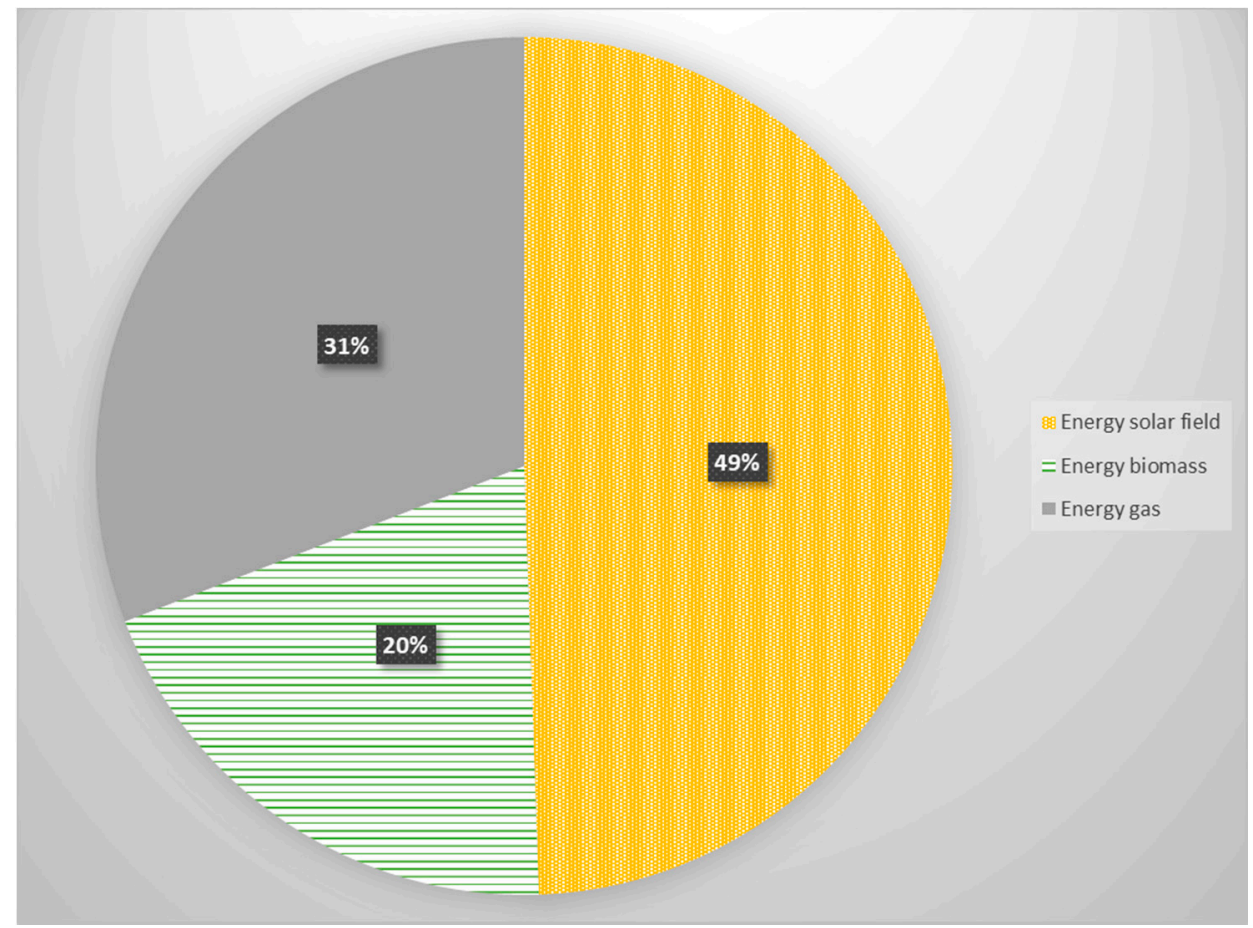

Figure 16. Distribution of energy supplied over the whole lifespan (connection 1).

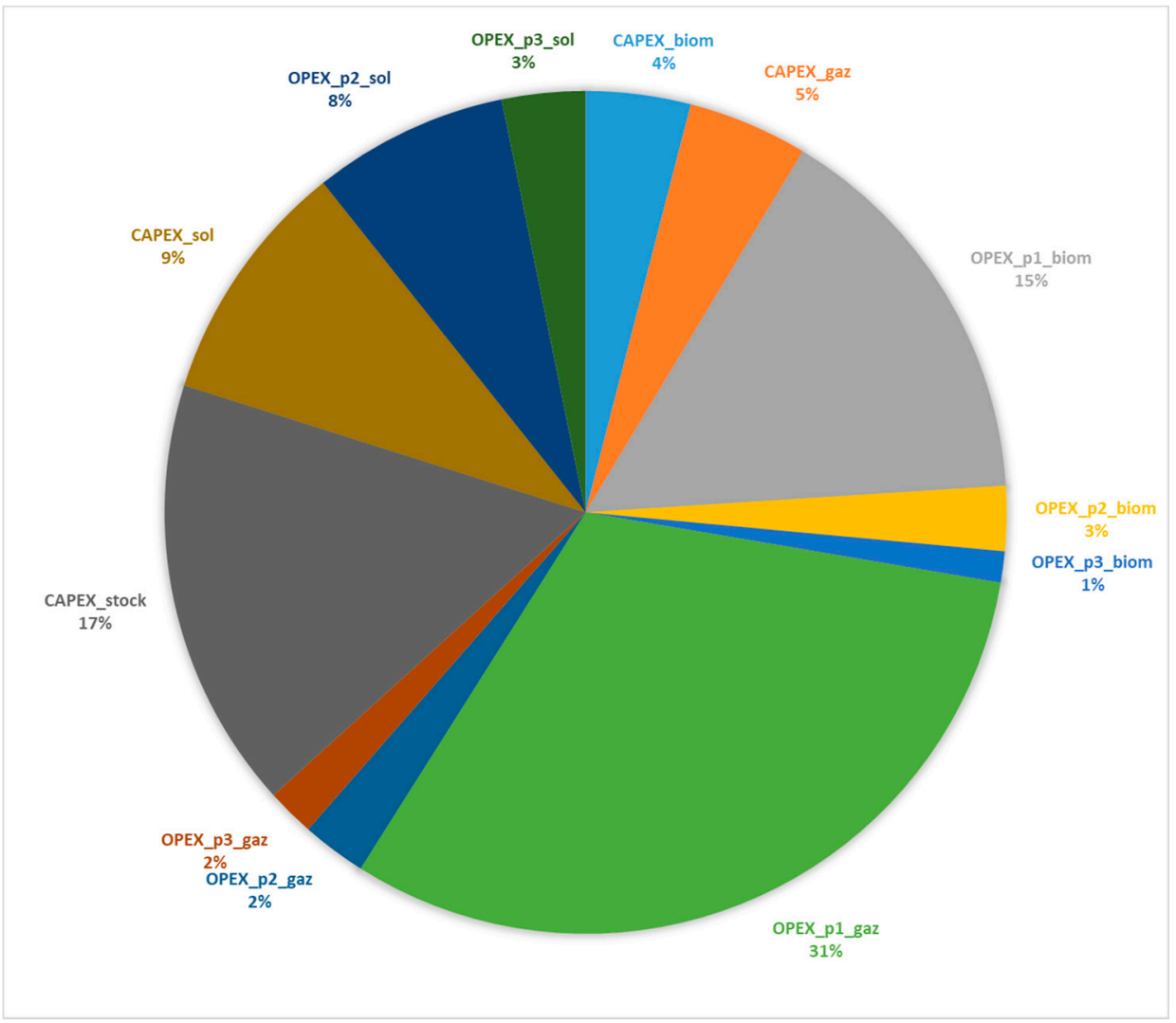

Figure 17. Distribution of costs over the whole lifespan (connection 1).

\section{Conclusions}

In the context of energy transition, heat production with low carbon emissions is needed. The use of solar thermal energy in heating networks in France but also in many 
other countries must be amplified. The possibility of optimizing the dimensioning of this type of system with the help of open-access tools will certainly help to increase the development of solar thermal energy. This study presents the methodology used in a new optimization tool written in Julia to size a thermal production site to supply a district heating network. The dynamic model of the system is discretized into a set of algebraic equations allowing the formulation of a multi-period nonlinear optimization problem. This model was applied to optimize the thermal production of a district heating network using inter-seasonal thermal storage. As nonlinear optimization guarantees neither systematic convergence nor a global optimum, a solution strategy was developed to guarantee a confidence optimum. Three thermal storage connections were studied, and the results showed the relevance of a storage connection at the solar field outlet. Results show that the model works properly and that the solar plant/storage couple is an interesting solution from an economic and environmental point of view. In fact, the economic optimum, taking state aid into account, assesses the value of solar energy at $49 \%$ of total energy supplied for a total renewable rate of $69 \%$. These first results also validate the choice of the Julia environment and the JuMP package for optimization. However, special attention must be paid to the problem-solving methodology to avoid getting a local minimum. The next step will be to apply this methodology to other types of networks, looking at existing networks, studying optimal operation or possible extensions and new networks where sizing will also be optimized with daily or inter-seasonal storage. Other perspectives are the consideration of other topologies of the production plan including parallel connections, consideration of cloudy days and their occurrence and computational time reduction.

Author Contributions: Conceptualization, R.D., S.S. (Sylvain Serra), S.S. (Sabine Sochard) and J.-M.R.; Data curation, R.D.; Formal analysis, R.D. and S.S. (Sylvain Serra); Funding acquisition, S.S. (Sylvain Serra); Methodology, R.D., S.S. (Sylvain Serra) and S.S. (Sabine Sochard); Project administration, S.S. (Sabine Sochard); Software, R.D.; Supervision, J.-M.R.; Validation, R.D., S.S. (Sylvain Serra) and J.-M.R.; Writing—original draft, R.D.; Writing—review and editing, S.S. (Sylvain Serra), S.S. (Sabine Sochard) and J.-M.R. All authors have read and agreed to the published version of the manuscript.

Funding: This research was funded by ADEME grant number 1805C0007 and the "Region NouvelleAquitaine". The APC was funded by LaTEP.

Acknowledgments: The authors would like to thank ADEME via the "Appel à projet de recherche ENERGIE DURABLE" and the "Region Nouvelle-Aquitaine" for providing funding for the ISORC/ OPTIMISER project. The authors also thank their partners (Tecsol, NewHEAT and Sermet) for their valuable advice.

Conflicts of Interest: The authors declare no conflict of interest.

\section{Nomenclature}

$\begin{array}{ll}A & \text { area, } \mathrm{m}^{2} \\ \mathrm{a}, \mathrm{b}, \mathrm{c} & \text { coefficients for functions } \\ \mathrm{C} & \text { product of } \dot{m} \text { and } C_{p}, \mathrm{~W} \mathrm{~K}^{-1} \\ C_{p} & \text { specific heat, } \mathrm{J} \mathrm{kg}^{-1} \mathrm{~K}^{-1} \\ C_{t o t} & \text { total costs, EUR } \\ \mathrm{E} & \text { efficiency } \\ G & \text { global Irradiance, } \mathrm{W} \mathrm{m}^{-2} \\ K & \text { using rate of boiler } \\ K_{\text {loss }} & \text { loss factor of storage, } \mathrm{s}^{-1} \\ k & \text { sigmoid coefficient, specific to use } \\ \dot{m} & \text { mass flow rate, } \mathrm{kg} \mathrm{s}^{-1} \\ n b y & \text { lifespan, years } \\ P & \text { power, } \mathrm{W} \\ \dot{Q} & \text { heat transfer, } \mathrm{W} \\ T & \text { temperature, }{ }^{\circ} \mathrm{C} \\ U & \text { overall heat transfer coefficient, } \mathrm{W} \mathrm{m}^{-2} \mathrm{~K}^{-1}\end{array}$




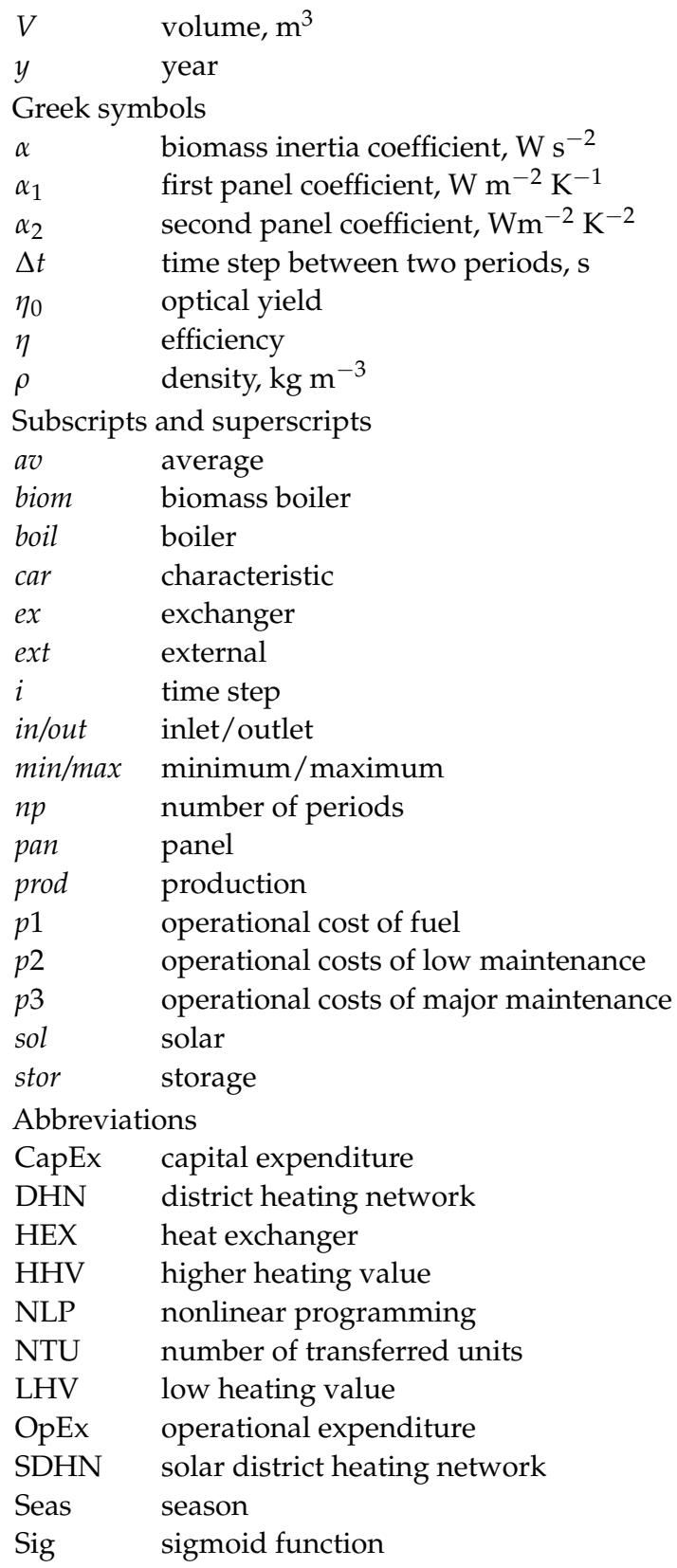

\section{References}

1. Dussud, F.-X.; Guggemos, F.; Riedinger, N. “Chiffres clés de L'énergie Edition 2018." Service de la Donnée et des études Statistiques (SDES). 2018. Available online: http:/ / reseaux-chaleur.cerema.fr/les-chiffres-cles-de-lenergie-edition-2018 (accessed on 20 October 2021).

2. ADEME (Agence de la Transition écologique). Se Chauffer Mieux Et Moins Cher; ADEME: Paris, France, $2014 ;$ p. 19.

3. Lund, H.; Werner, S.; Wiltshire, R.; Svendsen, S.; Thorsen, J.E.; Hvelplund, F.; Mathiesen, B.V. 4th Generation District Heating (4GDH): Integrating smart thermal grids into future sustainable energy systems. Energy 2014, 68, 1-11. [CrossRef]

4. Mazhar, A.R.; Liu, S.; Shukla, A. A state of art review on the district heating systems. Renew. Sustain. Energy Rev. 2018, 96, 420-439. [CrossRef]

5. Lake, A.; Rezaie, B.; Beyerlein, S. Review of district heating and cooling systems for a sustainable future. Renew. Sustain. Energy Rev. 2017, 67, 417-425. [CrossRef]

6. Sameti, M.; Haghighat, F. Optimization approaches in district heating and cooling thermal network. Energy Build. 2017, 140, 121-130. [CrossRef]

7. Werner, S. International review of district heating and cooling. Energy 2017, 137, 617-631. [CrossRef]

8. Wiltshire, R. Advanced District Heating and Cooling (DHC) Systems; Woodhead Publishing: London, UK, 2015.

9. Faninger, G. Combined solar-biomass district heating in Austria. Sol. Energy 2000, 69, 425-435. [CrossRef]

10. IEA TASK 55. Available online: https://task55.iea-shc.org/about (accessed on 25 October 2021). 
11. Gao, L.; Hwang, Y.; Cao, T. An overview of optimization technologies applied in combined cooling, heating and power systems. Renew. Sustain. Energy Rev. 2019, 114, 109344. [CrossRef]

12. Wang, Y.; Zhang, S.; Chow, D.; Kuckelkorn, J.M. Evaluation and optimization of district energy network performance: Present and future. Renew. Sustain. Energy Rev. 2021, 139, 110577. [CrossRef]

13. Mertz, T.; Serra, S.; Henon, A.; Reneaume, J.-M. A MINLP optimization of the configuration and the design of a district heating network: Academic study cases. Energy 2016, 117, 450-464. [CrossRef]

14. Marty, F.; Serra, S.; Sochard, S.; Reneaume, J.-M. Economic optimization of a combined heat and power plant: Heat vs electricity. Energy Procedia 2017, 116, 138-151. [CrossRef]

15. Marty, F.; Serra, S.; Sochard, S.; Reneaume, J.-M. Exergy Analysis and Optimization of a Combined Heat and Power Geothermal Plant. Energies 2019, 12, 1175. [CrossRef]

16. Marty, F.; Sochard, S.; Serra, S.; Reneaume, J.-M. Multi-objective approach for a combined heat and power geothermal plant optimization. Chem. Prod. Process Model. 2020, 16, 20200008. [CrossRef]

17. Powell, K.M.; Edgar, T.F. Modeling and control of a solar thermal power plant with thermal energy storage. Chem. Eng. Sci. 2012, 71, 138-145. [CrossRef]

18. Powell, K.M.; Cole, W.J.; Ekarika, U.F.; Edgar, T.F. Dynamic optimization of a campus cooling system with thermal storage. In Proceedings of the 2013 European Control Conference (ECC), Zurich, The Netherlands, 17-19 July 2013; pp. 4077-4082.

19. Powell, K.M.; Hedengren, J.D.; Edgar, T.F. Dynamic optimization of a hybrid solar thermal and fossil fuel system. Sol. Energy 2014, 108, 210-218. [CrossRef]

20. Scolan, S. Dynamic optimization of the operation of a solar thermal plant. Sol. Energy 2020, 198, 643-657. [CrossRef]

21. Nova-Rincon, A.; Sochard, S.; Serra, S.; Reneaume, J.-M. Dynamic simulation and optimal operation of district cooling networks via 2D orthogonal collocation. Energy Convers. Manag. 2020, 207, 112505. [CrossRef]

22. Suciu, R.; Kantor, I.; Bütün, H.; Maréchal, F. Geographically Parameterized Residential Sector Energy and Service Profile. Front. Energy Res. 2019, 7, 69. [CrossRef]

23. Casisi, M.; Pinamonti, P.; Reini, M. Optimal lay-out and operation of combined heat \& power (CHP) distributed generation systems. Energy 2009, 34, 2175-2183. [CrossRef]

24. Elsido, C.; Martelli, E.; Grossmann, I.E. Multiperiod optimization of heat exchanger networks with integrated thermodynamic cycles and thermal storages. Comput. Chem. Eng. 2021, 149, 107293. [CrossRef]

25. Kim, J.H.; Han, C. Short-Term Multiperiod Optimal Planning of Utility Systems Using Heuristics and Dynamic Programming. Ind. Eng. Chem. Res. 2001, 40, 1928-1938. [CrossRef]

26. Morvaj, B.; Evins, R.; Carmeliet, J. Optimising urban energy systems: Simultaneous system sizing, operation and district heating network layout. Energy 2016, 116, 619-636. [CrossRef]

27. Carpaneto, E.; Lazzeroni, P.; Repetto, M. Optimal integration of solar energy in a district heating network. Renew. Energy 2015, 75, 714-721. [CrossRef]

28. Buoro, D.; Pinamonti, P.; Reini, M. Optimization of a Distributed Cogeneration System with solar district heating. Appl. Energy 2014, 124, 298-308. [CrossRef]

29. Casisi, M.; Buoro, D.; Pinamonti, P.; Reini, M. A Comparison of Different District Integration for a Distributed Generation System for Heating and Cooling in an Urban Area. Appl. Sci. 2019, 9, 3521. [CrossRef]

30. Grossmann, I.E. Mixed-Integer Optimization Techniques for Algorithmic Process Synthesis. In Advances in Chemical Engineering; Elsevier: Amsterdam, The Netherlands, 1996; Volume 23, pp. 171-246. ISBN 978-0-12-008523-1.

31. Biegler, L.T.; Grossmann, I.E. Retrospective on optimization. Comput. Chem. Eng. 2004, 28, 1169-1192. [CrossRef]

32. Connolly, D.; Lund, H.; Mathiesen, B.V.; Leahy, M. A review of computer tools for analysing the integration of renewable energy into various energy systems. Appl. Energy 2010, 87, 1059-1082. [CrossRef]

33. Limpens, G.; Moret, S.; Jeanmart, H.; Maréchal, F. EnergyScope TD: A novel open-source model for regional energy systems. Appl. Energy 2019, 255, 113729. [CrossRef]

34. Limpens, G.; Jeanmart, H.; Maréchal, F. Belgian Energy Transition: What Are the Options? Energies 2020, 13, 261. [CrossRef]

35. Welcome I TRNSYS: Transient System Simulation Tool. Available online: http://www.trnsys.com/index.html (accessed on 4 December 2019).

36. Østergaard, P.A. Reviewing EnergyPLAN simulations and performance indicator applications in EnergyPLAN simulations. Appl. Energy 2015, 154, 921-933. [CrossRef]

37. Openmod-Open Energy Modelling Initiative. Available online: https://www.openmod-initiative.org/ (accessed on 4 December 2019).

38. Bezanson, J.; Karpinski, S.; Shah, V.; Edelman, A. The Julia Language. Available online: https://julialang.org/ (accessed on 12 December 2019).

39. Dunning, I.; Huchette, J.; Lubin, M. JuMP: A Modeling Language for Mathematical Optimization. SIAM Rev. 2017, 59, 295-320. [CrossRef]

40. Åberg, M.; Widén, J. Development, validation and application of a fixed district heating model structure that requires small amounts of input data. Energy Convers. Manag. 2013, 75, 74-85. [CrossRef]

41. Vesterlund, M.; Dahl, J. A method for the simulation and optimization of district heating systems with meshed networks. Energy Convers. Manag. 2015, 89, 555-567. [CrossRef] 
42. Pfenninger, S. Dealing with multiple decades of hourly wind and PV time series in energy models: A comparison of methods to reduce time resolution and the planning implications of inter-annual variability. Appl. Energy 2017, 197, 1-13. [CrossRef]

43. Kotzur, L. Time series aggregation for energy system design_ Modeling seasonal storage. Appl. Energy 2018, 213, 123-135. [CrossRef]

44. Domínguez-Muñoz, F.; Cejudo-López, J.M.; Carrillo-Andrés, A.; Gallardo-Salazar, M. Selection of typical demand days for CHP optimization. Energy Build. 2011, 43, 3036-3043. [CrossRef]

45. Lozano, M.A.; Anastasia, A.; Serra, L.M.; Verda, V. Thermoeconomic Cost Analysis of Central Solar Heating Plants Combined With Seasonal Storage. In Proceedings of the ASME 2010 International Mechanical Engineering Congress and Exposition, Vancouver, BC, Canada, 12-18 November 2010; pp. 643-653.

46. Sartor, K.; Quoilin, S.; Dewallef, P. Simulation and optimization of a CHP biomass plant and district heating network. Appl. Energy 2014, 130, 474-483. [CrossRef]

47. Loo, S.; van Koppejan, J. The Handbook of Biomass Combustion and Co-Firing; Earthscan: London, UK, 2008.

48. Roos, P.; Haselbacher, A. Thermocline control through multi-tank thermal-energy storage systems. Appl. Energy 2021, $281,115971$. [CrossRef]

49. van der Heijde, B.; Vandermeulen, A.; Salenbien, R.; Helsen, L. Representative days selection for district energy system optimisation: A solar district heating system with seasonal storage. Appl. Energy 2019, 248, 79-94. [CrossRef]

50. Solar District Heating. Available online: https:// www.solar-district-heating.eu/en/plant-database/ (accessed on 20 October 2021). 